\title{
LA PROYECCIÓN TERRITORIAL DE LOS PROTOMÉDICOS EN TIEMPO DE CARLOS V. EL DOCTOR DIEGO DE ZAVALLOS Y LAS CÉDULAS REALES EN SUSPENSIÓN DEL CAPÍTULO DE CORTES DE 1523*
}

\author{
Ignacio Ezquerra Revilla \\ IULCE, Universidad Autónoma de Madrid \\ CEDIS, FD-Universidade Nova de Lisboa, Portugal \\ ignacio.ezquerrarevilla@gmail.com
}

RESUMEN: En la Castilla tardomedieval y moderna la autorización administrativa para el ejercicio de la medicina se materializó en la concesión de licencias por los Ilamados alcaldes examinadores, antecedentes de los protomédicos. Desde su aparición, en tiempo de Juan I, surgieron roces con los municipios castellanos en torno a unas atribuciones que siempre les habían correspondido. Su actuación no conoció límites territoriales hasta que un capítulo de las Cortes de 1523 la limitó a la Corte y su perímetro de cinco leguas. Pero factores como -principalmente- la itinerancia europea de Carlos $V$ suspendieron de facto esta disposición, mediante una serie de cédulas reales que arrojaron gran confusión sobre el particular, tanto en su tiempo como para la crítica histórica. Este artículo pretende contribuir a aclararla.

Palabras clave: Alcaldes examinadores, Protomédicos, Consejo Real de Castilla, Doctor Diego de Zavallos, Corte.

\section{THE TERRITORIAL PROJECTION OF THE PROTOMÉDICOS IN TIME OF CARLOS V. THE DOCTOR DIEGO DE ZAVALLOS AND THE CÉDULAS REALES IN SUSPENSION OF THE CORTES OF 1523 CHAPTER}

ABSTRACT: In late-medieval and modern Castile, the administrative authorization for the practice of medicine materialized in the licensing by so-called alcaldes

* Este trabajo forma parte de los Projetos Estratégicos de Investigação UIDB/00714/2020 y UIDP/00714/2020, financiados en el CEDIS por la Fundação Ciência e Tecnologia (FCT), Ministerio da Ciência, Tecnologia e Ensino Superior, República Portuguesa. 
examinadores, predecessors of the protomédicos. Since its appearance, in the time of Juan I, frictions arose with the Castilian municipalities around attributions that had always corresponded to them. His action knew no territorial limits until a chapter of the Cortes of 1523 that limited it to the Court and its perimeter of five leagues. But factors such as - mainly - the European roaming of Carlos V actually suspended this order, through a series of royal decrees that threw great confusion on the matter, both in its time and for historical authors. This article aims to help clarify it.

Keywords: Alcaldes examinadores, Protomédicos, Royal Council of Castile, Doctor Diego de Zavallos, Royal Court.

Recibido: 12 de noviembre de 2019

Aceptado: 12 de marzo de 2020

\section{Introducción}

Aclarar la cuestión del alcance territorial efectivo de los protomédicos en el ejercicio de sus competencias en los reinos de Castilla tiene gran importancia, dado que implica medir los límites del gobierno doméstico extendido articulado por el rey, de orden oeconómico. Ha sido una cuestión marcada por la confusión, como confuso era un sistema político en el que la prolongación horizontal de la Cámara Real determinaba la unicidad del espacio sobre el que el monarca extendía su tutela en ese orden, de forma mediada y con diferentes grados de intensidad, y en el que, en consecuencia, lo administrativo y lo doméstico resultaban ámbitos sustancialmente indistinguibles. Este carácter no era exclusivo de la materia sanitaria, pero, en este caso, la espacialidad continúa emanada del ámbito restringido del rey derivaba de la condición de médicos de Cámara compartida por quienes ejercieron como protomédicos en la época moderna. De tal manera que la definición de esta figura era mucho más que un testimonio de la consolidación de un denominado "Estado moderno" centralizado y burocrático, como ha sido considerada por la mayor parte de la historiografía ${ }^{1}$, y bebía de tal entramado de orden doméstico y su correlato jurídico y social, el fortalecimiento de una idea de bien común ${ }^{2}$. A efectos prácticos, este cuadro se tradujo en la intervención de unos mismos individuos en un espacio continuo constituido por tres ámbitos, el espacio restringido del rey, la Corte entendida como lugar de permanencia del mismo y sus cinco leguas, y el territorio de los reinos de Castilla, si bien esa ac-

1. López Terrada, M. L., "Los tribunales del Protomedicato y el Protoalbeiterato", en López Piñero, J. M., dir., Historia de la ciencia y de la técnica en la corona de Castilla, III, Siglos XVI y XVII. Salamanca 2002, pp. 107-125, p. 107.

2. Quesada Sanz, J., "Algunos aspectos de la medicina en Murcia durante la época de los Reyes Católicos". Murgetana 6 (1954) pp. 53-97, pp. 56-57. 
tuación se vio sometida en su desarrollo a distintas circunstancias y tensiones que acotaron el contorno espacial y el contenido de unas funciones que, en cualquier caso, más o menos mediatizadas, siempre articularon un gobierno doméstico regio extendido. Se sustanciaban así en el campo médico las atribuciones paternales sobre sus súbditos que la doctrina política moderna confería al rey³.

La prolongación de la Cámara Real en el campo sanitario adquirió en Castilla la forma institucional del protomédico, juez encargado del examen y aprobación de los médicos y otros agentes sanitarios y el control del ejercicio de la profesión médica, con poderes disciplinarios y judiciales. Instituida la figura del alcalde examinador en tiempo de Juan I (1379-1390) para entender sobre las aptitudes de quienes deseaban ejercer la medicina o la cirugía, no tuvo un perfil más nítido hasta el reinado de Juan II $(1419-1454)^{4}$, y sus potestades fueron confirmadas por Enrique IV (1454-1474)5. Culminaba así el proceso de regulación de la profesión médica iniciado con la obtención por parte de los médicos de títulos universitarios que los equiparaban a otros profesionales, y acreditaban la posesión de los conocimientos y destrezas propias. Tales títulos autorizaban a sus titulares para ejercer la enseñanza o certificaban haber cumplido los cursos propios del plan de estudios, si bien posteriormente debían cumplir un periodo de visita a enfermos bajo la supervisión de un médico en ejercicio. Pero la novedad de la figura introducida residía en que, a partir de ese momento, el ejercicio de la medicina se vinculaba a la obtención de una licencia o "carta de examen" emitida por el señalado alcalde, que se convertía así en gestor de la concesión conforme a derecho de un documento que materializaba, en este orden médico, la potestad pública de autorización administrativa ${ }^{6}$. Esta denotaba cómo el referido sistema de gobierno doméstico extendido indujo la lenta definición de un ámbito meramente administrativo, crecido y maduro ya en el momento de la eclosión liberal?

\section{La paulatina definición del oficio de alcalde examinador y su actuación en el territorio de los reinos de Castilla}

El ejercicio de los alcaldes examinadores, y de sus sucesores los protomédicos, se vio afectado por un factor continuo, la fricción con las autoridades

3. Frigo, D. Il padre di famiglia. Governo della casa e governo civile nella tradizione del "economica” tra Cinque e Seicento. Roma 1985; Frigo, D., “Disciplinae Rei Familiariaé: a Economía como modelo administrativo de Ancien Regime". Penelope. Fazer e desfazer a História 6 (1991), pp. 47-62.

4. Barrio Ogayar, J., La organización del Protomedicato en España, Memoria para optar al Grado de Doctor en Medicina, Facultad de Medicina, Universidad de Granada. Dirigida por el Profesor José Luis Valverde López, 1989, p. 22.

5. Hernández Morejón, A., Historia crítica de la medicina española, I. Madrid 1842, p. 64.

6. Sobre el concepto, Laguna de Paz, J. C., La autorización administrativa. Cizur Menor (Navarra) 2006, especialmente pp. 35-37, 109 y 117-118.

7. Mannori, L., "Giustizia e amministrazione tra antico e nuovo regime", en Romanelli, R. (ed.), Magistrati e potere nella storia europea. Bolonia 1997, pp. 39-65. 
locales. Este carácter se apreció tanto en la época de su definición institucional, como en otras más avanzadas de la Edad Moderna castellana. No en vano, las facultades exclusivas asumidas por el poder real lo fueron en detrimento de los municipios, que mostraron su disconformidad con la novedad tanto en las Cortes de Zamora (1432) como en las de Madrigal (1438), al solicitar sin éxito la supresión de la figura del alcalde examinador. Ello no fue obstáculo para que las ciudades ignorasen de hecho las disposiciones reales y continuasen asegurándose de la idoneidad de los médicos que ejercieran en sus términos. Consta que el concejo de Murcia encargó a su médico oficial examinar a los aspirantes, y les confería o no la autorización para ejercer en función de lo decidido por él, como indica el caso del pretendiente David Abserga en 1465, examinado por el doctor Limiñana. En este ejercicio, se suscitaron estampas de gran tremendismo. Según refiere Quesada Sanz, en 1445 el cirujano Diego Sánchez, a modo de examen, extirpó un cáncer de mama en la Sala Capitular del concejo murciano, en presencia de los regidores ${ }^{8}$. Esta posición no desanimó a la corona, por el contrario, las atribuciones de los alcaldes examinadores fueron articuladas y ampliadas por la Ordenanza de Madrid de 30 de marzo de 1477 -publicada en forma de Pragmática-, que les confería junto a sus competencias originales el conocimiento de los crímenes o excesos cometidos por médicos y cirujanos, la exigencia de responsabilidades en el uso de sus oficios, la inspección de boticas, etc. ${ }^{9}$. La titulación de los médicos la otorgaban las universidades, pero la autorización para ejercer la conferían los alcaldes examinadores, que a su vez perseguiría el ejercicio médico sin licencia y las prácticas supersticiosas o hechiceras. En suma, quedaba formado un auténtico tribunal profesional, cuya actuación quedaba en lo sustancial fijada. La Pragmática de 1477 confirmó el desempeño como alcaldes examinadores de tres médicos reales: Juan Rodríguez de Toledo, Juan Texén y el maestre Juan de Guadalupe, quienes lo eran respectivamente desde tiempo de Enrique IV, abril de 1475 y julio de este mismo año, a quienes en ese momento se añadió el Doctor Lorenzo Badoz ${ }^{10}$.

\footnotetext{
8. Quesada Sanz, J., "Algunos aspectos de la medicina en Murcia durante la época de los Reyes Católicos", pp. 93-94.

9. Gómez Mampaso, V., "Los alcaldes examinadores mayores. Origen y competencia". Boletín de la Real Academia de la Historia 180 (1983), pp. 551-560. A su vez, para López Terrada la de 1477 fue la disposición decisiva, al introducir la posibilidad de la actuación colegiada (López Terrada, M. L., "Los tribunales del Protomedicato...", p. 108). Valverde, J. L., "El Tribunal del Protomedicato: composición, funciones, jurisdicción". Cuadernos Informativos de Derecho Histórico Público, Procesal y de la Navegación 1 (1986), pp. 7-28, p. 14, mantiene que la Ordenanza de 1477 se limitó a compendiar, sistematizar y ampliar las facultades y prerrogativas contenidas en las cartas de nombramiento de los físicos reales designados a partir de 1474.

10. González Arce, J. D., "Los proyectos de ordenanzas generales de médicos, cirujanos y boticarios de Castilla (ca. 1491-1513)". Dynamis 31 (1) (2011) pp. 207-226, p. 211. https://www. raco.cat/index.php/Dynamis/article/view/248585
} 
En este sentido, como indica González Arce, la nueva disposición se dirigía a corregir la actuación como órganos unipersonales autónomos entre ellos que hasta ese momento había caracterizado a los alcaldes examinadores mayores. No se puede descartar que esta fisonomía interna, tan diferente de lo que con el tiempo sería el "Tribunal del Protomedicato", tuviese un fundamento de orden doméstico y derivase del ejercicio facultativo simultáneo de los alcaldes en la Cámara Real, en la que la formulación de dictámenes y la imposición de la opinión tenían un criterio individual y no colegiado. Pero el resultado de la Pragmática fue muy limitado. La referida particularidad perjudicó la aprobación de unas ordenanzas uniformes para el ejercicio de la medicina en todo el territorio de los reinos de Castilla, que confiasen a la vía reglamentaria una tarea sometida en exceso a las atribuciones inspectoras y punitivas de los alcaldes, quienes supieron imponer su criterio técnico, personal y diferenciado entre sí sobre el voluntarismo legal del Consejo Real de Castilla. Pero, con ello, dada su condición simultánea de físicos reales, los alcaldes ejercieron de facto una administración sanitaria entreverada de gobierno doméstico regio extendido. Esta naturaleza indujo desde un principio prácticas que, con ser propias de tal forma de gobierno, perjudicaron la reputación de los alcaldes examinadores. Concebido su cargo como patrimonio propio, pronto pasaron a delegar sus funciones en comisarios, incluso mediante venta. A su vez, actuaban con un criterio personal y errático, tanto en la emisión de normativas locales, la realización de exámenes o la inspección de boticas. Pero, con todo, esa actuación implicaba, a través de los puntos geográficos en los que tenía lugar, la articulación de un proceso de integración espacial entre el ámbito reservado del rey y el territorio de los reinos.

Por todo ello, la oposición municipal no desapareció. En marzo de 1490 Rodríguez de Toledo y Guadalupe fueron comisionados por el rey para actuar en el caso de Luciano Genovés, boticario de Córdoba acusado por la justicia municipal de vender medicinas falsas o defectuosas. Genovés recurrió ante los alcaldes examinadores, quienes declararon la incompetencia del alcalde mayor de la ciudad para juzgar el caso, quien no obstante se negó a cederlo ${ }^{11}$. El tiempo venidero reveló una corona sensible a la posición municipal, en lo que influyó el carácter manifiesto de los abusos y cohechos cometidos hasta entonces en diferentes lugares por los tenientes de los alcaldes examinadores ${ }^{12}$. Un proyecto frustrado de Ordenanzas que regulara el ejercicio de la profesión médica, comentado y fechado por González Arce entre 1491 y 1497, culpaba a los alcaldes del ejercicio de boticarios completamente ineptos e ignorantes, al conferirles, pese a ello, licencia para ejercer el oficio, por lo que proponía

11. González Arce, J. D., "Los proyectos de ordenanzas generales de médicos, cirujanos y boticarios de Castilla...", pp. 209-210.

12. Campos Díez, M. S., El Real Tribunal del Protomedicato castellano (Siglos XIV-XIX). Cuenca 1999, pp. 33-34. 
devolver esa facultad a las autoridades locales, como se hacía en Castilla antes de la aparición de la figura de los alcaldes examinadores, y continuaba haciéndose en la corona de Aragón, donde la administración del ejercicio de la medicina tenía un mayor grado de desarrollo ${ }^{13}$. En 1494 fue declarada fraudulenta y opuesta al servicio real la designación de lugartenientes por ellos, quienes debían ejercer personalmente sus funciones, orden reiterada en Alcalá de Henares el 6 de abril de 1498, cuando fue publicada la "sobre carta del poder q[ue] los físicos y examinadores mayores de sus altezas tienen p[ar]a usar de sus oficios de alcaldes mayores, y p[ar]a que sirvan los officios por sus p[er]sonas y no por sostitutos"14. Con todo, si se repara en la denominación de esta disposición, se advierte cómo el ejercicio de la tarea médica estuvo dominado por la referida idea de la extensión doméstica, pues, implícitamente, el ejercicio como alcalde examinador se consideraba una función adicional a la de médico real. En este sentido, por entonces fueron otros dos médicos reales quienes entraron a formar parte del tribunal, Fernando Álvarez de la Reina y Juan de la Parra (médico procedente de la famosa escuela del Monasterio de Guadalupe), quienes se unieron al doctor Nicolás de Soto (físico del príncipe don Juan hasta su muerte), y el doctor Julián Gutiérrez ${ }^{15}$.

En una evolución claramente pendular, ahora fueron los alcaldes examinadores quienes ignoraron las indicadas disposiciones reglamentarias. Su actuación era legalmente inobjetable cuando permanecían en la Corte del Rey, pero la práctica de designar comisionados continuó pese a las disposiciones regias de 1494 y 1498 . En el primer caso, constan las Ordenanzas para el tratamiento de llagas peligrosas dadas en Toledo el 3 de septiembre de 1502 por los protomédicos Soto y Gutiérrez ante varios cirujanos locales, cuyas exigentes condiciones de aplicación levantaron amplia oposición entre la profesión ${ }^{16}$. En el segundo, en 1501 el doctor Nicolás de Soto, el doctor Julián Gutiérrez y el licenciado Alonso Fernández de Guadalupe, alcaldes examinadores mayores, designaron a Pedro Gómez de Fray Ague como su promotor fiscal en el obispado de Jaén y reino de Murcia, y al Bachiller Juan de Merlo, físico murciano, para perseguir

13. González Arce, J. D., "Los proyectos de ordenanzas generales de médicos, cirujanos y boticarios de Castilla...", p. 213.

14. García Gallo, A., ed., Libro de las Bulas y Pragmáticas de los Reyes Católicos, I, Madrid 1973, ff. CLIVv.-CLVv.

15. González Arce, J. D., "Los proyectos de ordenanzas generales de médicos, cirujanos y boticarios de Castilla...", p. 211. Sobre el Doctor de la Parra, Sebastián García, O.F.M., "Medicina y cirugía en los Reales Hospitales de Guadalupe". Revista de Estudios Extremeños 49 (2003) pp. 11-78, p. 65. El Doctor Julián Gutiérrez era físico de la reina Isabel desde 1 de enero de 1491 y a su muerte continuó ejerciendo en la casa real, percibiendo quitaciones entre el 1 de enero de 1505 y 1515, Jiménez Muñoz, J. M., Médicos y cirujanos en "Quitaciones de Corte". Valladolid 1977, p. 54.

16. González Arce, J. D., "Los proyectos de ordenanzas generales de médicos, cirujanos y boticarios de Castilla...", pp. 216-217. 
a los ejercientes sin carta de examen a su favor. En 1514 serían el doctor Julián Gutiérrez, y los doctores de la Reina y de la Parra, que desempeñaban entonces el oficio de alcaldes examinadores, quienes comisionaron al licenciado Pedro Frías al obispado de Jaén y adelantamiento de Cazorla, que tuvo muy serias fricciones con el adelantado, hasta el punto de ser encarcelado ${ }^{17}$.

Paulatinamente, el contenido de las cartas de nombramiento de los alcaldes mayores no solamente reguló su actuación, sino que reflejó con toda claridad que carecía de límites espaciales, superando la Corte entendida como lugar de permanencia del rey, aunque alguno debiera mantenerse en ella. De forma elocuente, si el rey era el polo de difusión doméstica, su cauce en este orden quedó constituido por los alcaldes examinadores-protomédicos. Podrían evaluar a los sanitarios, que de ser hallados idóneos recibirían cartas de examen y aprobación y licencia para el ejercicio profesional. También podrían castigar el ejercicio médico sin tal licencia, Ilamar ante sí a cualquier profesional sanitario (quienes estaban obligados a acudir) e inspeccionar las tiendas y boticas de boticarios, especieros y cualquier otro particular que vendiese medicinas y especias, para comprobar su bondad y conservación. En el plano jurisdiccional, entenderían de los pleitos civiles y criminales relativos a estas profesiones. Finalmente, velarían porque no fuesen empleados ensalmos, conjuros ni encantamientos en el ejercicio médico. En su tarea, estaban asistidos por un promotor fiscal y uno o varios porteros para emplazar a los profesionales, certificar plazos y penas y cobrar las penas aplicadas. Estas potestades podían ser ejercidas en cualquier lugar del reino, según se apreció también en un nuevo proyecto abortado de Ordenanzas, desarrollado entre 1510 y 1513 , cuya quinta cláusula ordenaba que los médicos denunciasen ante las justicias locales a los farmacéuticos que usaren mal su oficio o diesen medicinas falsas, "salvo sy en el tal lugar estovieren los dichos mis protomédicos o alguno dellos, porque en tal caso se ha de notificar a ellos para que lo punan e castiguen" ${ }^{\prime 18}$.

\section{La época de Carlos V. Limitación frustrada de la intervención territorial de los protomédicos}

En un principio, el reinado de Carlos $\mathrm{V}$ pareció recuperar la prohibición a los protomédicos -forma que se normalizó entonces para referirse a los que hasta entonces habían sido alcaldes examinadores- de designar lugartenientes, pero fue un espejismo que duró pocos meses. Por lo menos, la Cédula Real de Doña Juana y Don Carlos firmada en Valladolid el 15 de enero de 1518, al ordenar

17. Quesada Sanz, J., "Algunos aspectos de la medicina en Murcia durante la época de los Reyes Católicos", p. 94.

18. González Arce, J. D., “Los proyectos de ordenanzas generales de médicos, cirujanos y boticarios de Castilla...", pp. 212 y 222. 
que sólo y exclusivamente los protomédicos previamente designados por el monarca, el Maestre Liberal, el Maestre Juan Aberate y el Doctor Juan González de la Parra, "nuestros físicos del oficio", pudieran ejercer el oficio de protomédicos, parecía impedir implícitamente la designación de comisionados por su parte ${ }^{19}$. No obstante, parece que la falta de una declaración más explícita supuso la continuación de las tenencias, de tal manera que las Cortes de 1518, celebradas al mes siguiente $-y$, por lo tanto, con una cercanía cronológica que dificultaba valorar la efectividad de la orden- se refirieron en sus capítulos a la cuestión:

19. Otro sy, hazemos saber a vuestra alteza que los protomédicos por vuestra alteza nonbrados enbían por todo el reyno personas en su nonbre que bayan a visitar las boticas, lo qual se haze más por el interese que en ello se les sygue, concertándose con los que para ello enbían que les den parte del interese e de las penas, y van más a su ynteresse que non por bien del Reyno, a cuia cabsa se hacen muchas estersyones (sic) o agravios; suplicamos a Vuestra Alteza nos mande dar su provysyón, mandando que ningún médico que vaya a la dicha visytación pueda visytar ni condenar a nadie syno juntamente con otro médico de la cibdad o villa del Reyno que visytare, que les diere el rrejimiento, y anbos juntamente juren de hazer e guardar justicia ${ }^{20}$.

La respuesta regia distó de ser receptiva con la solicitud: "A esto vos respondemos que se probeerá sobrello lo que conbenga". Y ello tuvo ocasión de comprobarse tan pronto como el 15 de abril de ese mismo año, cuando una nueva Cédula Real ordenaba a las autoridades y justicias de todas las ciudades, villas y lugares de los reinos de Castilla que no impidiesen ejercer sus oficios a los protomédicos, y les diesen a ellos y a sus tenientes el favor y ayuda que fuese necesario: "...yo vos mando a todos e a cada uno de vos, que no os entremetáys en cosa alguna a lo tocante a los dichos ofiçios antes para el uso y exerçiçio dellos dad a sus sustitutos todo el favor e ayuda que vos pidieren o ovieren menester e de derecho aya lugar" ${ }^{\prime 21}$. De lo que no cabe duda es de que en el comienzo del reinado de Carlos de Habsburgo continuó la referida pauta de intervención territorialmente ilimitada de los protomédicos. El cumplimiento de la primera de las cédulas referidas se ordenaba "a los del nuestro Consejo, oydores de nuestras abdiençias, alcaldes e otras justiçias qualesquier asy de nuestra casa e corte e chançillería, como de todas las çibdades e villas e lugares

19. a Cédula ha sido publicada por García Gallardo, E., La documentación carolina en el Archivo Municipal de Murcia (1516-1525). Edición y estudio institucional, Tesis Doctoral Universidad de Murcia, 2017, pp. 137 y 227, http://hdl.handle.net/10201/55465.

20. Cortes de los Antiguos Reinos de León y de Castilla, publicadas por la Real Academia de la Historia, t. IV, Madrid 1882, p. 266.

21. Pub. en García Gallardo, E., La documentación carolina en el Archivo Municipal de Murcia (1516-1525)..., pp. 139 y 249. 
de nuestros reynos e señoríos...", y la segunda se dirigía a "Governadores, asistentes, corregidores, alcaldes, alguaziles, regidores, veynte e quatros, jurados e otras justiçias e personas qualesquier que agora soys e sereys de aquí adelante de todas e qualesquier çibdades, villas e lugares destos nuestros reynos e señoríos". Ya el año anterior, a poco de desembarcar en tierra española, don Carlos enfermó en San Vicente de la Barquera, y los protomédicos compatibilizaron la atención de la persona real en su condición de médicos de Cámara con el examen de aspirantes como el físico García Gutiérrez del Castillo. Hallado hábil, el 7 de octubre de 1517 recibió título que le facultaba para ejercer en todo el territorio castellano ${ }^{22}$. En un contexto de creciente consistencia institucional, la transferencia espacial ejercida por los médicos de Cámara en su calidad de protomédicos, era una característica manifiesta de su actuación, coherente con la articulación de un gobierno político de matriz doméstica regia.

Una nueva Cédula Real de 15 de noviembre de 1519, firmada por el ya emperador en Molins de Rei, dirigida al Doctor Don Luis Marliano, obispo de Tui, y al Doctor Liberal Turvesyno, sus protomédicos, profundizaba en la línea señalada al autorizarles a nombrar delegados que ejerciesen sus funciones en su nombre, mientras ellos permanecían en compañía real fuera de los reinos de Castilla. Dos días antes, esta decisión era comunicada en otra Cédula Real a todos los concejos de Castilla ${ }^{23}$. De esta manera, una característica apuntada ya en tiempo de los Reyes Católicos cobraba fuerza en el del emperador, la relación entre la itinerancia regia, de radio más extenso en tiempo de Carlos V dada su dimensión europea, y dos rasgos propios de los protomédicos: la falta de límites espaciales en su intervención, extendida al conjunto del territorio castellano, y la potestad plenamente legal de designar lugartenientes que actuasen en su nombre en ese espacio. Las Cortes de Santiago de 1520 asimilaron tan clara postura regia y sólo alcanzaron a pedir que tales tenientes conociesen su oficio y fueran acompañados en sus comisiones por médicos locales, a lo que el emperador respondió que había ordenado al Consejo tratar del particular con los protomédicos ${ }^{24}$.

22. Campos Díez, M. S., El Real Tribunal del Protomedicato castellano..., p. 54. Desembarcado en la playa de Tazones, a una legua de Villaviciosa, el 19 de septiembre de 1517, procedente de Colombres llegó a San Vicente de la Barquera el día 29, donde hubo de permanecer indispuesto hasta el día 12 de octubre, cuando salió todavía enfermo hacia Treceño, Cadenas y Vicent, V. de, Diario del Emperador Carlos V (Itinerarios, permanencias, despacho, sucesos y efemérides relevantes de su vida). Madrid 1992, pp. 108-109.

23. Cédulas publicadas por García Gallardo, E., La documentación carolina en el Archivo Municipal de Murcia (1516-1525), pp. 142 y 302-303.

24. "33. Así mesmo suplican a V. M. mande proveer que los protomédicos de V. M. cuando enbíen a visitar las boticas, enbíen personas de ciencia e concencia, e que no puedan vesitar ni condenar a nadie sino juntamente con otro médicos de la ciudad o villa del reyno, e vesiten con aquél que les diere el regimiento, y ambos juntamente juren de haver e guardar justicia". A ello el emperador contestó que "yo he mandado a los de mi Consejo que hablen 
La tendencia cambió en el contexto de las alteraciones comuneras. Como es sabido, la Corona combinó la represión de los sublevados con la asimilación implícita de parte de sus demandas, especialmente en lo referido a la regeneración del sistema administrativo ${ }^{25}$, y la contestación regia a los capítulos de Cortes de 1523 reflejó ya esa actitud. De ese marco formó parte la atención prestada, nuevamente, a los protomédicos, tanto como el más categórico lenguaje empleado al respecto por los procuradores, y la propia respuesta real, responsable de una limitación parcial del alcance territorial de sus atribuciones, con todo -según su redacción-, ambigua y poco clara. La petición número 46 daba por sentada la defectuosa e ineficaz actuación de los protomédicos, solicitaba un examen complementario por parte de las justicias municipales, proponía nuevamente la figura del acompañado local cuando los primeros hubieran de visitar físicos, cirujanos y boticas de un lugar determinado y concluía retomando la solicitud de que no pudiesen nombrar subdelegados ${ }^{26}$. La respuesta regia fue:

A esto vos rrespondemos que nos plaze que nuestros prothomédicos, que son o fueren, examinen por sus personas sin poner sustitutos, los físycos y cirujanos y boticarios en nuestra Corte, con çinco leguas alrrededor, y que fuera de las dichas çinco leguas, no puedan llamar ni traher persona ninguna, y que la visitaçión de las boticas la hagan por sý mesmos, y en lo que fuere fuera de las çinco leguas, mandamos quel nuestro corregidor o justiçia ordinaria, con dos rregidores e un físyco aprovado del tal lugar haga el examen de las dichas boticas ${ }^{27}$.

Como se aprecia, la respuesta regia iba más allá de lo solicitado por los procuradores, y en ello no es difícil apreciar un deseo de apaciguamiento, que encontró su marco, simbólico y material, en la asamblea de Cortes. Un

con los protomédicos en ello para que se dé la orden que conbenga al bien del Reyno, los quales lo harán assí", Cortes de los Antiguos Reinos de León y de Castilla,..., IV, p. 328.

25. Haliczer, S., Los comuneros de Castilla: la forja de una revolución (1475-1521). Valladolid 1987, pp. 259 ss.; Rady, M., Carlos V, Madrid 1991, p. 67.

26. "46. Iten; hazen saber a Vuestra Magestat que los prothomédicos, por muy poco preçio e yntereses, dan cartas de examen a personas ynábiles y de poca espiriençia en la çirugía e medicina, de que rresulta gran daño e perjuyzio; por ende, suplicamos a Vuestra Magestat mande que los tales físycos y cirujanos examinados por los dicjos prothomédicos puedan ser rreexaminados por la justiçia e regimiento donde los tales físycos eçirujanos exerçieren sis ofiçios, y que para mayor seguridad y buen rregimiento, quando los prothomédicos quisieren vesytar los dísicos, çirujanos e noticas, tomen por acompañado una persona quel regimiento nonbrare y no la puedan hacer sin él, e que los tales prothomédicos no puedan subdelegar vesytadores", Cortes de los Antiguos Reinos de León y de Castilla,... , IV, p. 379.

27. Cortes de los Antiguos Reinos de León y de Castilla,..., IV, p. 379. Extractado en Biblioteca de Castilla y León, Signatura ge-f_26, manuscrito. También en García Gallardo, E., La documentación carolina en el Archivo Municipal de Murcia (1516-1525)..., op. cit., p. 477, Cédula Real de 24 de agosto de 1523 a todas las autoridades y concejos con las peticiones de las asambleas de Cortes y sus respuestas. 
contexto político excepcional y muy concreto hizo más por limitar el radio de acción de los protomédicos que las repetidas solicitudes en este sentido de las autoridades locales, formuladas desde la misma definición de los alcaldes examinadores. Por lo demás, la redacción de la respuesta era imprecisa. Una lectura atenta y al pie de la letra de la misma daría por fijadas tres cuestiones: el examen personal y la visita de las boticas a cargo de los propios protomédicos en el perímetro de las cinco leguas; la prohibición de "llamar ni traher persona ninguna" más allá de ese espacio; y la visita de las boticas fuera del espacio de las cinco leguas a cargo de las autoridades locales. Pero otros muchos puntos que venían caracterizando la actuación de los protomédicos quedaban sin mencionar. Si se repara en ello, quedaba abierta la posibilidad de designar delegados más allá de las cinco leguas, o, si bien se prohibía de forma un tanto ambigua "llamar ni traher" a nadie de ese espacio, nada se decía de examinar en él, hecho significativo si se considera que la del examen era la atribución principal de tales ministros.

Parecía querer hacerse compatible una disposición transigente con las ciudades, con un hecho que, directa e indirectamente, terminó anulando de facto la disposición: la itinerancia regia, que implicaba la deambulación sobre la plataforma de los reinos de ese perímetro de actuación restringido, cuando no, en el caso de Carlos V, la propia ausencia del monarca. Con todo, pese a la escasa claridad de su redacción, que la disposición se percibió como una limitación de índole territorial de la labor de los protomédicos se dedujo, paradójicamente, de las repetidas cédulas reales que en adelante suspendieron su aplicación y, con ello, extendieron la confusión sobre el particular. Otra de las consecuencias implícitas de la contestación real a la petición de Cortes, apreciada por María Soledad Campos Díez, y confirmada por la documentación que pronto será citada, fue que su conocimiento quedó limitado a los médicos, cirujanos y boticarios, con exclusión de ensalmadores, especieros y herbolarios ${ }^{28}$.

En primer lugar, las fuentes permiten deducir que, al menos en parte de su contenido, la referida disposición tuvo un escaso cumplimiento, de manera que las Cortes de Madrid de 1528 -en su capítulo 124-, adujeron el reiterado ejercicio de físicos, cirujanos y boticarios sin ser graduados y sin haber estudiado en estudios generales el periodo estipulado de diez años, pero con carta de examen a favor expedida por los protomédicos, para solicitar al rey que estos realizasen el examen personalmente, "syn lo cometer ni dar poder a otra persona" y cerciorándose de que los aspirantes habían recibido la formación requerida. En el caso de los boticarios, exigencias adicionales fueron el conocimiento del latín y habilidad demostrada en la elaboración de fármacos simples y compuestos. A su vez, todos los profesionales sanitarios deberían mostrar su titulación a las justicias del lugar donde pretendiesen ejercer. Por

28. Campos Díez, M. S., El Real Tribunal del Protomedicato castellano..., pp. 53-54. 
única respuesta, el emperador declaró haber sometido la petición al criterio del Consejo Real ${ }^{29}$.

A su vez, la serie de ausencias regias de los reinos de Castilla que se abrió en adelante no fue un contexto idóneo para que la norma de 1523 se impusiese como criterio de actuación de los protomédicos. Tales desplazamientos denotaron las consecuencias, en un gobierno de matriz doméstica, de la práctica simultánea como médico de Cámara y protomédico, dado que, al necesitar el emperador de la atención médica in itinere de los primeros, privaba a los reinos de Castilla del ejercicio de los segundos. Con ocasión de la jornada de la entrevista y paz de Bolonia con el Papa, en 1529-1530, consta el servicio en ella de los doctores Escoriaza, Zaballos y de Ávila, quien tenía además el cargo de protomédico ${ }^{30}$. Ante la necesidad de designar protomédicos que cubriesen esa ausencia, la emperatriz-regente doña Isabel nombró por Cédula Real en Madrid a 24 de septiembre de 1529 al Doctor Miguel Zurita de Alfaro, médico real, y al Doctor Çalaya, "médico estante en n[uest]ra Corte", en principio con observancia -incluso acentuada- del capítulo aprobado en las Cortes de 1523, dado que actuarían "... anbos a dos juntamente e no el uno syn el otro e con que no hos entremetáys a llamar ny apremyar a nyng[un]a p[er]sona salbo a aquellos q[ue] stán en n[uest]ra Corte e dentro de cinco leguas alrededor della e q[ue] no estvuieren exsamynados o obieren estado en costumbre de curar mucho t[iem] po, e q[ue] las p[er]sonas q[ue] examináredes las exsamynéys en n[uest]ra Corte e no fuera della ny déys poder a otra p[er]sona q[ue] lo aga...". A su vez, la cédula confirmaba la señalada intuición de Campos Díez, dado que continuaba señalando que "... ansymysmo no uos entremetáys a exsamynar ni ensalmadores ny p[ar]teras ny espeçieros ny drogueros ny otra p[er]sona alguna más de los susod[ic] hos ofiçios e çurujanos e boticarios e barberos..." ${ }^{31}$.

El nombramiento del Doctor Miguel Zurita de Alfaro (padre del cronista Jerónimo Zurita) como protomédico en realidad implicaba renovar una condición que ya había tenido. Tras haber recibido título de Doctor en Medicina en Barcelona el 25 de junio de 1510, una cédula de Doña Juana y Don Carlos en Zaragoza de 15 de enero de 1519 le nombró físico de su casa. Acumuló a esta condición la de protomédico en todos sus reinos y señoríos a partir del 22 de septiembre de este último año, a las que se añadió la de examinador mayor de todos los físicos,

29. Cortes de los Antiguos Reinos de León y de Castilla,... , IV, Madrid 1882, pp. 506-507.

30. Archivo General de Simancas (AGS). Estado (E), leg. 21, fol. 22, pub. en Beltrán de Heredia, V., Cartulario de la Universidad de Salamanca: la universidad en el Siglo de oro, II. Salamanca 1970, p. 519. El Doctor Zavallos, de quien me ocuparé cumplidamente en este texto, era médico de la Casa Real del emperador desde el 8 de marzo de 1529, Jiménez Muñoz, J. M., Médicos y cirujanos en "Quitaciones de Corte"..., p. 108; Campos Díez, M. S., El Real Tribunal del Protomedicato castellano..., p. 377.

31. AGS. Consejo Real de Castilla (CRC), leg. 93, nº 5-I, cfr. la transcripción en apéndice, número 2. 
boticarios, ensalmadores, herbolarios y especieros en todos los reinos y señoríos por privilegio real de 1 de marzo de 1523. En el entretanto, se ocupó de la atención médica del gobernador Adriano de Utrecht. Sus repetidos servicios a las personas reales no hicieron sino aumentar el aprecio regio por su tarea. El 5 de septiembre de 1525 el emperador le ordenó atender a su prisionero Francisco I, quien se encontraba enfermo. Asimismo, una carta real de 3 de abril de 1529, en Zaragoza, testimonió el profundo agradecimiento del emperador por haber asistido a su esposa enferma ${ }^{32}$.

Sin embargo, pronto se hicieron patentes las dificultades de los dos nombrados para hacer efectiva esta cédula, o más correctamente, valerse de ella para actuar en todo el espacio territorial castellano. Parece que interpretaban la ausencia real como una licencia implícita para superar un límite espacial que sólo la presencia de la persona real determinaba, aunque la letra de la propia cédula conforme al capítulo de 1523 legitimaba la resistencia de los municipios más allá de ese límite. Por ello recurrieron a la regente, quien expidió una nueva Cédula Real sobrecartada la anterior, en Madrid el 20 de junio de 1530 (mientras se celebraba la Dieta de Augsburgo), que les permitía actuar individualmente -y no insolidum como la anterior- y les autorizaba a ejercer el oficio "no embargante que estubiesen absentes de n[uest]ra Corte e fuera de las cinco leguas della", ordenando a los municipios "que libremente los dexéys e consintáys usar del d[ic] ho of[ici]o de $\mathrm{n}$ [uest]ros prothomédicos a cada uno dellos por sý haziendo la d[ic]ha uisytaçión p[er]sonalmente en los casos y cosas contenydas en la d[ic] ha my çédula q[ue] desuso ua incorporada..." ${ }^{\prime 33}$. Conforme a este texto, se aprecia cómo, convertida la regente con la ausencia del rey-emperador en su alter ego jurisdiccional, el referido espacio cortesano era el determinado por su propia persona, cuyo sentido limitador, con todo, quedaba en suspenso con tal disposición.

Terminada la jornada, se hizo patente cómo el servicio médico personal al monarca era mérito propio para ocupar el cargo de protomédico, un cursus implícito asumido por los aspirantes y el propio emperador. A su conclusión, los doctores Escoriaza y Zaballos y el Maestre Nicolao Flamenco suplicaron se les diese facultad para usar el oficio de protomédicos, mientras el doctor de Ávila solicitó recibir en su casa su salario como tal ${ }^{34}$. En todos los casos, el emperador accedió a lo solicitado, puesto que con ocasión del nuevo desplazamiento real

32. Cuartero y Huerta, B.-Vargas Zúñiga y Montero de Espinosa, A. de, Índice de la Colección de Don Luis Salazar y Castro, IX. Madrid 1953, p. 30. Falleció en Toledo el 23 de enero de 1539, y el 9 de noviembre del año siguiente era extendido un certificado sobre su servicio como protomédico, Jiménez Muñoz, J. M., Médicos y cirujanos en "Quitaciones de Corte"..., p. 109.

33. AGS. CRC, leg. 93, no 5-I, cfr. la transcripción en apéndice, número 2.

34. AGS. E, leg. 21, fol. 22, pub. en Beltrán de Heredia, V., Cartulario de la Universidad de Salamanca..., II, p. 519. El Doctor Escoriaza también solicitó percibir 669.707’5 mrs. que 
a Túnez, una Cédula Real firmada en Barcelona el 18 de abril de 1535, dirigida a evitar la usurpación del oficio por terceros, trataba como tales protomédicos a los doctores Escoriaza, Zavallos y Alfaro y al Maestre Nicolás, protomédico de Aragón ${ }^{35}$, quienes se habían dividido en el servicio regio. Mientras Alfaro y Escoriaza permanecieron en Castilla, Zavallos y el Doctor Maestre Nicolás acompañaron al emperador ${ }^{36}$. La cédula relativa a la usurpación del oficio tenía relación con la intercesión realizada por el Consejo Real en la última Consulta de Viernes anterior a la partida de Carlos V, en favor del Doctor Çalaya, quien, como aludí, ejerció de protomédico con cédula de la emperatriz durante la ausencia anterior. El emperador accedió, y consultado también con doña Isabel, hizo lo propio, de manera que Çalaya comenzó a ejercer el oficio, pero el primero parecía haber olvidado o rectificado su primera decisión, y dejó de practicar en cuanto recibió la cédula de 18 de abril. En consulta de 8 de mayo, el Consejo pedía a Carlos V sumar a Çalaya a Álfaro y Escoriaza, "por ser la persona que es y teniendo rrespeto a lo que ha seruido e sus letras y esperiençia, pareçería que por alguna otra causa o defecto suyo es remobido..." ${ }^{37}$.

A lo largo de la Jornada, desarrollada de marzo a octubre, los cuatro protomédicos suscribieron un convenio sobre derechos y honores profesionales, y los desplazados a Italia efectuaron comisiones relativas a médicos y boticarios en diferentes poblaciones ${ }^{38}$. El referido desempeño múltiple de la plaza de protomédico dejó memoria administrativa. Cuando en 1585 las Cortes de Castilla plantearon remedios para el defectuoso desempeño del Doctor Olivares como protomédico, los informes regios mencionaron que tanto Carlos $\mathrm{V}$ como su hijo habían tenido la costumbre de conferir la plaza de protomédico difunto a todos los médicos de Cámara, de manera que había llegado a haber tres, cuatro y hasta cinco que actuaron simultáneamente, como indicaba el hecho de que en 1535 la carta de examen del boticario Espinosa apareciese firmada por los doctores Alfaro, Çaballos, Escoriaza, Florenis y Çalaya ${ }^{39}$. Si damos por buena esta

se le adeudaban de su salario y ayuda de costa desde 1520, para ayuda al cumplimiento del casamiento de una hija.

35. AGS. Cámara de Castilla (CC), Libros de Cédulas, lib. 95/2, fol. 5, pub. en Beltrán de Heredia, V., O.P., Cartulario de la Universidad de Salamanca..., II, p. 456.

36. Una Cédula Real de 26 de mayo de 1535, en Barcelona, ordenaba librar a los doctores Zavallos, Moreno y de Ávila, "nuestros médicos", y al Doctor Guadalupe, "nuestro cirujano" sus quitaciones, "pues están y residen acá en mi servicio", Jiménez Muñoz, J. M., Médicos y cirujanos en "Quitaciones de Corte"..., p. 108.

37. AGS. Guerra Antigua (GA), leg. 7, fol. 45.

38. Baltasar Cuartero y Huerta, B. y Vargas Zúñiga y Montero de Espinosa, A. de, Índice de la Colección de Don Luis Salazar y Castro, IX, p. 31.

39. AGS. Patronato Real (PR), 78-142, "En la prouisión del Prothomedicato conuiene aduertir lo pri[mer]o que siempre ha sido costumbre de Su Mag[estad] y del Emperador N[uest] ro S[eño]r que aya gloria dar el Prothomedicato a todos los médicos de Cámara q[ue] quedan quando el Prothomédico muere, y assí ha auido tres y quatro y çinco prothomédicos q[ue] en tiempo del Emperador N[uest]ro S[eño]r q[ue] es en gloria, lo fueron juntos, Alfaro, Çauallos, 
afirmación, cabe deducir que finalmente la intercesión del Consejo en favor de Çalaya había sido atendida. De vuelta en Castilla, una nueva Cédula Real firmada en Valladolid el 25 de noviembre de 1537 concedía a los doctores Florenis y Zaballos las ventajas previamente gozadas por Zurita de Álfaro y Çalaya por la cédula de 20 de junio de $1530^{40}$.

\section{El Doctor Diego de Zavallos, médico de cámara y protomédico real}

En lo relativo al Doctor Zavallos (o Zeballos, Zevallos, Zaballos o Ceballos, que de estas y todavía más formas es referido en las fuentes), la citada documentación permite acotar con algo más de precisión el momento de acceso a la condición de protomédico, que debió tener lugar en torno a la conclusión de la jornada italiana de $1530^{41}$. Pese a la falta de datos biográficos abundantes y sistemáticos, merece la pena detenerse en su trayectoria. Puesto que si se puede reconstruir la complicada evolución del protomedicato en tiempo de Carlos V, y arrojar luz sobre la compleja cuestión de su efectivo alcance territorial, es gracias a la información contenida en el proceso que le fue incoado por el Consejo Real a instancia de su fiscal, el licenciado Contreras, en 1554. Fue entonces cuando las tensiones de Zavallos con la autoridad municipal cacereña pusieron fin a la intervención territorial ilimitada de los protomédicos, amparada hasta ese momento por la deambulación europea de Carlos V. Con la llegada del Doctor Zavallos a la Cámara Real, primero, y al protomedicato, después, se consolidaba en la Corte la escuela médica del monasterio de Guadalupe, pues se le puede considerar depositario de más de un siglo de ciencia médica desarrollada en su hospital ${ }^{42}$. La primera noticia de la relación de Zavallos con el cenobio de las Villuercas data de 31 de mayo de 1510, fecha en la que el capítulo ponía impedimentos a su deseo de desplazarse a Bugía con don García de Toledo, invocando su vinculación por diez años de duración con el monasterio. En

Escoriaça, Florenis, Çalaya. Y año de 35 todos juntos examinaron y dieron carta a Espinosa Boticario $[\ldots]^{\prime \prime}$.

40. AGS. CRC, leg. 93, n 5-I, ff. 64r.-65r., cfr. apéndice, número 2.

41. Fray Arturo Álvarez, O.F.M., "Un ilustre protomédico de Carlos V: el Doctor Ceballos". $A B C$ Sevilla, 14 de noviembre de 1958, pp. 3-5, p. 5, situaba su acceso a la plaza entre 1521 y 1537.

42. Dado que casó con una hija del Doctor Juan de la Parra, discípulo de los hermanos Maestre Rodrigo, cirujano, y Maestre Juan de Guadalupe, cirujano y médico de los Reyes Católicos, ambos hijos, a su vez, de otro famoso cirujano de Guadalupe, Maestre Pedro, Alonso Cortés, N., Dos médicos de los Reyes Católicos, Separata de Hispania XLV, s.a, p. 636. Breves reseñas biográficas de Juan de Guadalupe, Juan de la Parra y el Doctor Zavallos en Sebastián García, O.F.M., "Medicina y cirugía en los Reales Hospitales de Guadalupe", pp. 64-65. Respecto a sus estudios, Solís de los Santos, J., "Zavallos, Diego de", Diccionario Biográfico Español (edición electrónica), http://dbe.rah.es/biografias/86598/diego-de-zavallos aventura que obtuvo su grado en medicina en la Universidad de Salamanca. 
marzo de 1519 el capítulo le negaba un aumento de sueldo, por sus frecuentes ausencias sin autorización, pero ello no implicaba poco aprecio por su figura, dado que el prior, fray Juan de Siruela, envió en octubre de 1521 sendas cartas de recomendación en su favor al presidente de Castilla y al príncipe don Fernando, avalando ya sus virtudes para la plaza de protomédico ${ }^{43}$. A partir de ese momento debió atraer la atención cortesana, como se deduce del hecho de que atendió la salud de la emperatriz Isabel desde su llegada a Castilla en $1526^{44}$. Con todo, como indicaba en nota, no alcanzó plaza de médico de la Casa Real hasta el 8 de marzo de 1529, para permanecer al servicio del emperador, con nombramiento adicional como protomédico, entre 1531 y 1549 , cuando le fue concedida licencia para regresar a España ${ }^{45}$.

A continuación de los servicios ya indicados, a los que cabe añadir la aprobación de libros médicos derivada de su condición de protomédico ${ }^{46}$, constó su presencia en la comitiva del emperador cuando partió el 21 de noviembre de 1539 de Valladolid para atravesar Francia rumbo a los Países Bajos, a raíz del levantamiento de Gante ${ }^{47}$. La itinerancia regia no fue una situación apropiada para la estabilidad del servicio médico imperial. Por carta de Carlos $V$ al secretario Cobos de 5 de agosto de 1540, desde La Haya, conocemos sus quejas porque los doctores Almazán y Montaña no habían atendido su llamada para desplazarse junto a él, hecho que implicó el despido de este último, y su decisión de sustituirlos por los doctores del Águila (perteneciente así mismo a la escuela médica de Guadalupe) e Irure, quien servía al príncipe Felipe. Dado el perfil de los elegidos, en la elección probablemente influyó el doctor Zavallos, el único que permanecía fielmente junto al emperador, "... que no puede dar recaudo a los que adolecen, y los enfermos pasan mucho trabajo..." ${ }^{\prime 4}$. Desde posición tan eminente en el servicio real, Zavallos ejerció sus funciones con amplia discrecionalidad, excediendo unos límites originalmente ceñidos a Castilla. Consta que por privilegio real de 15 de mayo de 1541 declaró Protomédico de Ma-

43. Fray Arturo Álvarez, O.F.M., "Un ilustre protomédico de Carlos V: el Doctor Ceballos", pp. 3-5.

44. Martínez Millán, J. (dir.), La Corte de Carlos V, vol. V, Los servidores de las casas reales. Madrid 2000, p. 94. Entró a servir junto a Juan Rodríguez.

45. Campos Díez, M. S., El Real Tribunal del Protomedicato castellano..., p. 377.

46. Caso de De ratione minuendi sanguinem in morbo laterali liber non inutilis, obra de Jorge Gómez publicada en Toledo por Juan de Ayala en 1539, Solís de los Santos, J., "Zavallos, Diego de", Diccionario Biográfico Español...

47. Solís de los Santos, J., "Zavallos, Diego de", Diccionario Biográfico Español...

48. Beltrán de Heredia, V., Cartulario de la Universidad de Salamanca..., II, p. 466 (nº 505) (transcripción de AGS. E, leg. 50, fol. 250). En pago a su fiel servicio, el emperador ordenó la libranza de sus quitaciones a Zavallos y el Doctor Francisco Serras "nuestro cirujano", "... que han venido y están aquí en mi servicio todo el tiempo que durare su ausencia de los Reinos de Castilla sin pedirles fe de residencia", por cédula en Bruselas de 30 de septiembre de ese año, Jiménez Muñoz, J. M., Médicos y cirujanos en "Quitaciones de Corte"..., p. 109. 
Ilorca al Magnific Joan Andreu, Doctor en Medicina ${ }^{49}$. La exclusividad en sus atribuciones llegó el 30 de noviembre de 1544, cuando el emperador declaró su voluntad de "no proveer otro protomédico ni que haya más del dicho doctor" si bien el Doctor Ledesma, médico de la Inquisición, ejerció como su teniente. La distancia no fue obstáculo para ejercer, como indica el hecho de que revisó, antes de su publicación en Valladolid en 1551, el conocido Libro del Regimiento de Salud del Doctor Luis Lobera de Ávila. Entre los méritos indicados por el autor en carta al emperador fechada en Valladolid el 6 de marzo de 1545 -para solicitar merced de gentilhombre o contino para su hijo- constaba esta obra, que indicaba estar allá (Bruselas) en poder del doctor Zavallos ${ }^{51}$. Aunque una aprobación formal por parte del protomédico no formó parte de los preliminares de la obra, su decisiva intervención se deduce del hecho de que culminaban con un "Catálogo de los yllustres y doctíssimos médicos de nuestro tiempo", abierto por el "Doctor Çauallos protomédico de Su Magestad"52. De la relación que contenía se deduce que, como indicaba, el Doctor Ledesma, médico de la Inquisición, ejercía al tiempo como teniente del protomédico.

Tan encumbrada posición médica induce a pensar que, al margen de sus dotes, se fundaba en un sólido apoyo político, y las noticias de que disponemos permiten deducir que se encontraba bajo la muy protectora sombra de Francisco de los Cobos, según se puso de manifiesto con ocasión de su fallecimiento en mayo de 1547. Con Zavallos en Castilla desde que el emperador decidió el 20 de marzo de ese año que quedase al servicio del príncipe don Felipe ${ }^{53}$, cuando al mes siguiente el todopoderoso secretario empeoró su salud, víctima de un

49. Campaner y Fuentes, Á., Cronicón Mayoricense. Noticias y relaciones históricas de Mallorca desde 1229 a 1800. Palma de Mallorca 1984, p. 257, apud Sampietro Solanes, M. J., La comunicación científico-médica en Mallorca (1560-1760): bibliotecas de médicos, boticarios y cirujanos e introducción de medicamentos chymicos, Tesis Doctoral Universidad de las Islas Baleares, 2015, p. 124, http://hdl.handle.net/11201/148988

50. Beltrán de Heredia, V., Cartulario de la Universidad de Salamanca..., II, pp. 525-526.

51. AGS. E., leg. 72, fol. 33, transcrita por C. P. Gredilla en "Variedades", Revista de Archivos, Bibliotecas y Museos 3 (1873) pp. 146-152, p. 152.

52. A quien seguían el doctor Andrés Vesalio, médico de Su Majestad; los doctores del Águila y Moreno, médicos de Cámara del príncipe; el doctor Abarca, médico del emperador y de Cámara de la reina de Bohemia; los doctores Francisco de Almazán, Montaña, Irure y Pero López, todos ellos médicos de Su Majestad; el doctor Ledesma, médico de la Inquisición y teniente del protomédico; los doctores Rodríguez, Peñaranda y Céspedes, catedráticos en Valladolid; los doctores León y Vega, catedráticos en Alcalá; el doctor Reinoso, catedrático en Coimbra; el doctor Alderete, catedrático en Salamanca; los doctores del Hierro y Cabra, médicos en Sevilla; el doctor Inquilina (sic), médico en Córdoba; el doctor Aguilar, médico en Toledo; el doctor Fabricio, médico en Segovia y el doctor Vega, médico en Ávila, Libro del regimiento de la salud, y de la esterilidad de los hombres y mugeres, y de las enfermedades de los niños y otras cosas utilíssimas. Compuesto por el doctor Avila de Lobera, médico de Su Magestad..., [Valladolid], 1551.

53. Solís de los Santos, J., "Zavallos, Diego de", Diccionario Biográfico Español. 
ataque de fiebres tercianas, su médico, el doctor Villarroel, requirió su presencia en Úbeda. Que debía unirle algún vínculo de orden amistoso o clientelar con Cobos se deduce del hecho de que informó que todavía había esperanza de curación al Conde de Morata -con quien permanecían en Zaragoza el hijo y la nuera del secretario-. Pero el 1 de mayo se recibieron noticias alarmantes, y don Diego de los Cobos se puso en camino de inmediato, el día 4 el secretario firmaba su testamento y el 10 falleció. Entre los testigos de la firma de sus últimas voluntades estuvo el doctor Zavallos ${ }^{54}$. Con la muerte del secretario Cobos, cabía aventurar un debilitamiento de su posición, pero este fue provisionalmente desmentido por su presencia en el servicio que acompañó al príncipe Felipe en su jornada europea iniciada en $1548^{55}$. Con todo, el nuevo contexto político manifestado por el propio viaje no tardó en afectar a Zavallos. Concedida licencia temporal por el emperador para regresar a Castilla, su protección le permitió, en un principio, sortear las dificultades. Pero ya se barruntaba el nuevo escenario propio del acceso a la corona de Felipe II, bajo el dominio del partido ebolista, que terminaría implicando un apartamiento sólo frustrado por la propia muerte del protomédico.

De regreso en Castilla y en ejercicio de su oficio según sus prerrogativas, y no conforme a las limitaciones impuestas en 1523, el fiscal del Consejo defendió estas últimas, le acusó de visitar "lo que le estaba prohibido por no ser de su oficio" y le prohibió examinar a drogueros, especieros y parteras, al tiempo que le imponía nuevas limitaciones "en derogaçión de los títulos y provisiones que de nos tiene y de las pregmáticas hechas por los cathólicos reyes n[uest] ros agüelos...". Ante ello, Zavallos protestó a Carlos $V$ y este firmó una Cédula en Bruselas el 23 de diciembre de 1549 con la orden para el fiscal de no hacer novedad en tanto regresaba a Castilla. Esa cédula fue sobrecartada en Augusta el 12 de septiembre de 1550, nuevamente a petición del Doctor, ante la inobservancia de la misma por parte del fiscal, que incluso le había abierto proceso formal ${ }^{56}$. En consecuencia, el Doctor Zavallos continuó en el libre ejercicio de su oficio y, así, consta que el 7 de abril de 1551 concedió licencia para curar 299.

54. Keniston, H., Francisco de los Cobos: secretario de Carlos V. Madrid 1980, pp. 295 y

55. Una certificación expedida en Bruselas el 12 de junio de 1549 dio fe de su servicio en la Corte itinerante del príncipe desde su partida de Valladolid el 1 de octubre de 1548 hasta su llegada a Bruselas el 1 de junio de 1549, momento en que Zavallos se reincorporó al servicio del emperador, Jiménez Muñoz, J. M., Médicos y cirujanos en "Quitaciones de Corte"..., p. 109.

56. AGS. CRC, leg. 93, no 5-I, f. 60r.-v, ver apéndice, número 1. La documentación contenida en la referida carpeta de este legajo, relativa al proceso que afectó al Doctor Zavallos en 1554 (que luego referiré), es fundamental para conocer el alcance práctico del protomedicato castellano en tiempo del emperador, y fue citada y utilizada anteriormente por Clouse, $\mathrm{M}$. L., Medicine, government and public health in Philip II's Spain: shared interests, competing authorities. Farnham, Burlington 2011, p. 30. 
de cirugía en Valladolid a Alonso de Castrillo, quien con posterioridad ejercería en $\mathrm{Chile}^{57}$. Por lo demás, por entonces pudo comprobarse que la falta de limitación territorial en su actuación no fue una potestad gozada a título personal por Zavallos, sino una atribución propia por entonces del oficio que ejercía. Consta que a comienzos de la década de 1550 su compañero el Doctor Gutiérrez intervino con decisión ante la emisión de licencias para el ejercicio médico por parte de diferentes ciudades, especialmente Granada, cuyo contenido autorizaba para ejercer en el conjunto de los reinos de Castilla. Ante ello, propuso la creación de un sello oficial en poder del protomédico que hiciese legales tan solo las licencias por él emitidas ${ }^{58}$.

Pero los impedimentos por parte del Consejo Real no cesaron y Zavallos se desplazó nuevamente ante la persona del emperador, quien firmó nuevas cédulas reales en Augusta el 18 de mayo de 1551, una que le concedía licencia definitiva como médico real "para que pueda yr a España y estar ausente de nuestra Corte y servicio residiendo en su casa o donde le pluguiere desde el día de la fecha de esta nuestra cédula que partió de esta nuestra Corte en adelante hasta que sea de vuelta en aquellos nuestros reinos sin que se le descuente cosa alguna de su salario" ${ }^{\prime \prime 5}$. Y una segunda relativa a su oficio de protomédico, que sobrecartaba las cédulas publicadas desde 1529 en suspensión de las limitaciones espaciales del ejercicio de los protomédicos y ordenaba taxativamente que "le dexéys e consyntáys usar y exerçer el d[ic]ho su of[ici]o de prothomédico en estos d[ic]hos n[uest]ros reynos e señoríos libremente syn lo poner embaraço ny ynpedimento alg[un]o no embargante qualquier ley o premática q[ue] en contr[ari]o aya con las quales por sola esta uez nos dispensamos... contanto $q[$ [ue] $d[i c]$ ho dotor por su p[er]sona syn lo cometer a otra p[er]sona use y exerza el d[ic]ho of[ici]o". De forma explícita se añadía que las visitas tocantes a su oficio serían hechas en presencia de los corregidores o justicias de las ciudades, villas y lugares "donde se hallare y estubiere según e de la man[er]a q[ue] lo exercita y usa en n[uest]ra Corte e cinco leguas alrededor"60, lo que implicaba dejar nuevamente en suspenso la disposición emanada del capítulo de las Cortes de 1523. El estatuto del Doctor Zavallos continuó incólume incluso después de nuevas medidas sobre el oficio tomadas por Cédula Real de 24 de mayo de 1552. Tan solo tres días después, una nueva Cédula Real, en esta ocasión del propio Príncipe Felipe refrendaba la vigencia de las cédulas firmadas por su padre el 23 de diciembre de 1549 y el 12 de septiembre de $1550^{61}$.

57. Cano Roldán, I., La mujer en el Reyno de Chile. Municipalidad de Santiago, 1981, p. 373; VV. AA., Colección de historiadores de Chile y documentos relativos a la historia nacional. Imprenta del Ferrocarril, 1898, p. 112.

58. Clouse, M. L., Medicine, government and public health in Philip II's Spain..., pp. 30-31. 59. Transcrita en Jiménez Muñoz, J. M., Médicos y cirujanos en "Quitaciones de Corte"..., p. 109. 60. AGS. CRC, leg. 93, nº 5-I, ff. 64r.-65r., cfr. apéndice, número 2.

61. AGS. CRC, leg. 93, no 5-I, f. 62r. 
Lo cierto es que desde su publicación, pese al agitado contexto que la había originado, las sucesivas asambleas del reino habían acatado implícitamente las disposiciones regias que dejaban en suspenso la petición concedida en las Cortes de 1523, y aquellos capítulos que habían tocado la tarea de los protomédicos se habían centrado en otros aspectos, antes que la continuidad y amplitud territorial de su actuación. Hecho que, de paso, permite anteponer los aspectos de orden político en la derogación final de tal legislación limitadora, antes que la tensión entre la corona y los municipios. En la misma línea, la prohibición de que los protomédicos enviasen comisarios fuera de las cinco leguas, aprobada como resultado de la petición 12 de las Cortes de 1538-39, implicaba que su tarea debía ser realizada personalmente. Es cierto que, al tiempo, la petición 74 de la misma asamblea solicitó al rey la intervención de la justicia municipal en el caso de los cirujanos "ydiotas e indoctos", aunque estuviesen previamente habilitados por los protomédicos ${ }^{62}$. Pero el capítulo 24 de las Cortes de 1542 solicitó, incluso, la designación de protomédicos en cada ciudad o villa cabeza de partido, petición que, bien mirado, podía constituir un hábil intento de transferir al ámbito municipal la designación de tales oficiales y el control de la profesión médica ${ }^{63}$.

Por su parte, la petición CXIX de las Cortes de 1548, pese a formularse cuatro años después de la asunción exclusiva del oficio de protomédico por parte del doctor Zavallos, dejaba ver el efecto local de la actuación espacialmente ilimitada de los protomédicos nombrados durante la ausencia regia, al actualizar los reproches que tradicionalmente se hacían a su figura: la recaudación arbitraria de derechos, reprobando a los hábiles para que repitieran el examen, y aprobando por dinero a los torpes. La súplica expresa de supresión del oficio y transmisión de sus atribuciones a las justicias ordinarias era la mejor prueba de la derogación de facto de la disposición de 1523 y la vigencia efectiva de las cédulas posteriores que suspendían su contenido. Del mismo modo que la respuesta, encomendando al Consejo la revisión de la reglamentación tocante y la discusión sobre el particular ${ }^{64}$, insinuaba el fin de una situación mantenida en el tiempo que, sin embargo, estaba marcada por la interinidad de la ausencia real.

Con todo, la petición CXXXVIII de las Cortes de 1551 continuó centrada en el contenido de la labor de los protomédicos y no en su alcance espacial, al pro-

62. Esta disposición formó la ley $4^{\mathrm{a}}$, título XVI, libro III de la Recopilación de las leyes destos reynos, hecha por la Magestad Católica del Rey don Felipe Segundo nuestro señor.... Madrid 1640 [ed. facsímil Valladolid 1982], y la 3a, título X, libro VIII de la Novísima, Cortes de los Antiguos Reinos de León y de Castilla publicadas por la Real Academia de la Historia, t. V, Madrid 1903, pp. 138-139.

63. Cortes de los Antiguos Reinos de León y de Castilla..., V, p. 212.

64. "Cortes de Valladolid de 1548 y las pragmáticas y capítulos que S. M. del Emperador y Rey nuestro Señor hizo en las Cortes que se tovieron con el serenísimo Príncipe D[o]n Phelipe nuestro señor en su nombre. En Valladolid año de 1548", Cortes de los Antiguos Reinos de León y de Castilla..., V, p. 422. 
poner cambios en la forma de examen que practicaban, de manera que se comprobase el conocimiento del latín por parte de boticarios y cirujanos, lengua en la que estaban escritos los libros en los que aprendían y usaban sus oficios, así como su práctica previa durante al menos cinco años. A su vez, los protomédicos deberían ser acompañados al realizar el examen por persona de autoridad que evitase el despacho de cartas de examen inmerecidas, ni estas serían dadas en ausencia, sujetas a condiciones de práctica o formación suplementaria -que luego no eran cumplidas-, o conferidas a individuos sin titulación universitaria. Para el reino uno de los motivos de conductas así era la levedad de la pena impuesta, consistente en 3.000 mrs. de multa, por lo que propuso la aplicación de pena corporal, así como un castigo de cien azotes para aquellos médicos que no mostrasen su título y licencia ante la justicia del lugar en el que ejerciesen. La respuesta real encomendó a los protomédicos la guarda genérica de lo legislado respecto a su oficio ${ }^{65}$, pero, con ello, dibujaba un horizonte muy limitado al ejercicio del doctor Zavallos como protomédico, que, como hemos apreciado, se fundaba en circunstancias excepcionales.

\section{El litigio ante el Consejo Real}

El protomédico tuvo en adelante ocasión de comprobarlo con el mero ejercicio de su oficio, puesto que su labor fue objeto de un proceso en el que, significativamente, la argumentación contraria a la figura del protomédico sostenida tradicionalmente por las asambleas de Cortes pasó a fundamentar las acusaciones formuladas en su contra por el propio fiscal del Consejo Real. Los obstáculos puestos a la actuación del doctor Zavallos en la villa de Cáceres le llevaron a querellarse contra el licenciado Pedro Sánchez, teniente de corregidor, ante la Chancillería de Granada, que emitió sendas provisiones el 20 de julio de 1553 y el 23 de febrero de 1554 obligando a la justicia municipal a respetar el contenido de las cédulas ganadas en su favor por Zavallos y no poner impedimentos a su actuación ${ }^{66}$. En su alegato, la autoridad cacereña adujo que el ejercicio del protomédico tenía lugar solamente "quando el susod[ic] ho estvuiese en $\mathrm{n}$ [uest]ra Corte y cinco leguas a la redonda o quando fuere de camyno"67, pero este argumento, que en realidad las aludidas cédulas suspendían, se debía a una disputa por los derechos devengados por el ejercicio de la inspección médica en la villa, de la que el Doctor Zavallos era natural. La inmediata evolución de los acontecimientos que describo a continuación pivota sobre este hecho. Para el momento en que llegó la provisión

65. "A esto vos respondemos, que mandamos que los prothomédicos guarden las leyes y pregmáticas, e lo nuevamente proveydo y mandado, por lo qual se remedia lo contenido en esta petición", Cortes de los Antiguos Reinos de León y de Castilla..., V, p. 560.

66. AGS. CRC, leg. 93, no 5-I, f. 58r.-v.

67. Se adopta el tono subjetivo propio de las cédulas y provisiones reales. 
de la Chancillería de Granada, el Consejo ya le había ordenado no usar de su oficio y comparecer ante él ${ }^{68}$, dado que, al margen de lo decidido por la Chancillería, su labor había atraído la atención del fiscal, dado que la mera sospecha de actuación irregular desentonaba con la idea de regeneración que debía acompañar el cada vez más previsible acceso del príncipe Felipe al trono y la simultánea instalación del partido ebolista en el poder ${ }^{69}$. De hecho, el propio organismo era objeto entonces de visita por Don Diego de Córdoba, bajo la atenta supervisión del propio Príncipe. El doctor Zavallos llevaba dos años de visita por tierra extremeña, concluyendo como protomédico real inspecciones en las villas de Alcántara, Las Brozas, Arroyo el Puerco, Badajoz y Alburquerque, entre otros lugares, y se hallaba haciendo lo propio en Cáceres cuando surgió el litigio con sus autoridades ${ }^{70}$.

El 3 de abril de 1554 el licenciado Contreras, fiscal del Consejo, presentó ante el organismo su querella contra Zavallos, con argumentos semejantes a las ya indicadas peticiones de Cortes críticas con la actuación de los protomédicos: "... a hecho muy grandes vexaciones, agrauios y estorsiones y lleuado gran cantidad de dineros no lo pudiendo hazer ni lleuar,... especialmente dando licencias a personas ynábiles p[ar]a q[ue] curasen de enfermedades no lo pudiendo hazer por razón de su ynabilidad ansí hombres como mugeres por q[ue] se lo pagaban muy bien sin preceder examen de las dichas personas ni estar presentes". Era el primero de una serie de cargos que también pasaban por privar de ejercicio a médicos habilitados para ganar los derechos que pagaban para recuperar la licencia, darla a parteras sin examen previo, omitir la visita de la villa de Arroyo el Puerco previo pago por su concejo, inducir la intervención de médicos sin licencia mediante un criado que fingía estar enfermo para imponerles penas, etc. Por todo ello, el fiscal solicitaba al Consejo que el protomédico fuera privado de su oficio ${ }^{71}$.

En su descargo, presentado el 6 de abril, el Doctor Zavallos no sólo adujo la debilidad jurídica de los testigos aportados por el fiscal (puesto que eran los propios perjudicados por su tarea), sino que abundó en argumentos que no dejaban en buen lugar el control e inspección médica ejercidos por la autoridad local, aquellos que originalmente habían dado impulso a la propia definición de la figura del protomédico. De ser ciertos, la oposición a su intervención de don Juan del Castillo, corregidor de Cáceres, se debía al interés de este último

68. AGS. CRC, leg. 93, n 5-I, f. 67r., provisión real en Valladolid de 8 de febrero de 1554 firmada por el Presidente Antonio de Fonseca, el licenciado Galarza, el licenciado Otalora, el doctor Ribera, el doctor Diego Gasca y el doctor Velasco, con Castillo como secretario.

69. Martínez Millán, J., "Grupos de poder en la Corte durante el reinado de Felipe II: la facción ebolista, 1554-1573", en Martínez Millán, J., coord., Instituciones y élites de poder en la Monarquía Hispana durante el Siglo XVI. Madrid 1992, pp. 137-198.

70. AGS. CRC, leg. 93, no 5-I, f. 71r.

71. AGS. CRC, leg. 93, no 5-I, f. 52r.-v. 
en ganar las sumas derivadas de la visita y a su amistad con el doctor Bernáldez, médico de la villa. Quien era además su fiador en su juicio de residencia, cubría sus necesidades económicas y no deseaba que cierto boticario con quien tenía amistad recibiese la inspección del protomédico. Al margen de ello, de haber incurrido en alguna de las responsabilidades atribuidas, Zavallos creía estar legalmente cubierto para hacerlo e, incluso, en algunos casos la pena impuesta era mucho más leve de lo que podía haber sido. Sí había visitado las boticas de Arroyo el Puerco, donde quemó muchas medicinas falsas y dañosas y, en cuanto a su criado, negó la acusación con razones que inducían a pensar lo contrario. Si hubiese fingido enfermedades, "... era buena yndustria y cautela p[ar]a descubrir los delinquentes e p[er]sonas q[ue] en p[er]juizio de los enfermos e de su salud querían usar sus ofi[ci]os q[ue] no saben ni tienen lic[enci] a ny exsamen dello". A todo ello añadió la cobertura legal que le ofrecían las cédulas reales ganadas y el aval recibido de la propia Chancillería de Grana$\mathrm{da}^{72}$. Entretanto, Zavallos no dejó de actuar como tal protomédico pese a estar suspendido y, para escándalo del fiscal, autorizó el ejercicio como saludador a Martín Sánchez, vecino de Santisteban ${ }^{73}$. A su vez, consta que en torno a esas fechas examinó en Cañamero al licenciado Ponte, bachiller en medicina por Salamanca ${ }^{74}$.

Sin embargo, el contexto que rodeaba a Zavallos desde su regreso debilitaba su posición, tanto por el alejamiento del servicio personal al emperador, como por las señaladas mutaciones de orden político. Estas ayudaron a que la mención explícita de su actuación, según la interpretaba el Consejo, no tardase en llegar a oídos de Carlos V. El organismo le transmitió cómo el procurador del común de Cáceres había solicitado al corregidor que abriese información "... de ciertos agrauios que dizque fazía en ella el doctor Çaballos...", entre los que destacaban:

... a dado licencias a personas ynábiles para que curen de enfermedades así a hombres como a mujeres porque se lo pagauan y sin estar presentes y priuaba a otros que heran ábiles y los suspendía que no curasen y si se lo pagaban les tornaba a dar liçençia y abilitaua para curar y a mujeres pobres de tierra de la d[ic] ha uilla de Cáceres parteras las fazía parecer ante sí y por usar el ofiçio de parteras les lleuaua dineros y a otras sin las hexaminar dio licencia para usar el oficio de parteras ${ }^{75}$.

72. AGS. CRC, leg. 93, no 5-I, f. 54r.-55r.

73. Alegación del licenciado Contreras para que esta conducta fuese añadida a la causa, presentada ante el Consejo Real el 7 de julio de 1554, AGS. CRC, leg. 93, no 5-I, f. 72r.-v.

74. Según constó en la presentación de títulos académicos realizada por los opositores a la cátedra de Cirugía en la Universidad de Salamanca realizada el 27 de noviembre de 1597, Beltrán de Heredia, O. P., V., Cartulario de la Universidad de Salamanca: la universidad en el Siglo de Oro, IV. Salamanca 1972, p. 495.

75. AGS. E, leg. 109, no 91, consulta del Consejo al emperador de 19 de marzo de 1555. 
La incredulidad se apoderó del emperador, incapaz de concebir un comportamiento inapropiado en su médico de Cámara y protomédico, que no había dudado en abandonar Castilla para atender su salud, a cambio de más penurias y riesgos que dinero. Sin embargo, la respuesta recibida del príncipe Felipe cuando le consultó sobre el particular no dejaba lugar a dudas: "paresçe que está bien lo proveído por el Consejo y que el doctor guarde y cumpla lo que les paresçe". Sin embargo, el negocio estaba lejos de estar sustanciado, y ello animó al emperador a ordenar al Consejo que le avisase antes de que lo estuviera $^{76}$. Por el momento no dispongo de evidencias, pero no es descabellado pensar que, con ello, la causa no llegara a tener sentencia firme, especialmente si se tiene en cuenta la abdicación de Carlos $V$ consumada al poco tiempo ${ }^{77}$. Además, la publicación de una sentencia tenía una importancia relativa, pues la cuestión central, el uso por Zavallos de sus privilegios, había quedado ya aclarada por provisión del Consejo Real en Valladolid el 22 de enero de 1555, que ordenaba:

entretanto q[ue e]l negocio se consulta con Su M[ajes]t[ad] el d[ic]ho dotor no use de las cédulas y sobreçédulas q[ue] tiene de Su M[ajes]t[ad] para q[ue] fuera de las cinco leguas de la Corte y en aq[ue]llos casos o cosas contenydas en la premática q[ue] sobrello habla use su ofiçio y q[ue e]I d[ic]ho dotor pueda usar de oficio de protomédico y uesite y examyne conforme a los capítulos de Corte q[ue] sobrello hablan y no en otra manera ${ }^{78}$.

Además, tan sólo tres meses después llegaría la muerte del propio doctor ZavaIlos, acontecida en Valladolid, en casa del doctor Abarca, el 2 de abril de $1556^{79}$. Dictó testamento el día anterior, en el que se titulaba "médico de la Cámara de Su Magestad y su protomédico en todos los sus reinos y señoríos", de manera que, para esa fecha, la condena solicitada por el fiscal Contreras seguía sin ser firme.

76. "En lo que toca al doctor Çavallos, visto las quexas que dél han venido al Consejo por los excesos que ha hecho en el exerçiçio del officio de prothomédico y el auto que en el Consejo se havía pronunciado y lo que más dizen, paresçe que está bien lo proveido por el Consejo y que el doctor guarde y cumpla lo que les paresçe, entretanto que el negoçio se torna a ver $y$ determinar, y que V. M. embíe a mandar al Consejo que antes de determinarlo en revista, avisen a V. M. particularmente del estado del negocio y de lo que sobre él les parescerá, para que entonces $\mathrm{V}$. M. mande lo que más convenga a su servicio", carta del príncipe Felipe a Carlos V, Hampton Court, 1 de junio de 1555, en Fernández Álvarez, M., ed. lit. Corpus Documental de Carlos V, IV. Salamanca 1979, p. 221.

77. Por lo menos, en el legajo del que saco el grueso de la documentación consultada para este trabajo, AGS, CRC, leg. 93, cuyos números 5-10 están dedicados a las probanzas del proceso, no hay ni rastro de la sentencia.

78. AGS, CRC, leg. 93, $n^{\circ}$ 5-1, fol. 80r.

79. Jiménez Muñoz, J. M., Médicos y cirujanos en "Quitaciones de Corte"..., p. 108, indica como fecha de su muerte el día siguiente. 
En el documento se apreciaba su fuerte vinculación extremeña, pues se declaraba vecino de La Puebla de Guadalupe y disponía ser sepultado en la iglesia del monasterio "en la sepoltura de mi muger", si bien si fallecía como consecuencia de la enfermedad que padecía en ese momento, como terminó sucediendo, debía serlo "en la yglesia adonde mis testamentarios les paresçiere desta villa de Valladolid adonde esté hasta que sea tiempo de me llebar al dicho monesterio de Guadalupe[...]"80. Ese momento no Ilegó hasta el 14 de enero de 1562, según el "Libro de sepulturas de seglares y religiosos extraños a Guadalupe" conservado en el Archivo del Monasterio ${ }^{81}$. Su sobrina doña Margarita de Paz llevó en dote a su matrimonio la cédula de asiento como médico real para quien casase con ella ${ }^{82}$.

\section{Conclusión. El nuevo reinado: la vigencia formal de la disposición de 1523}

En el plano administrativo, con el proceso y muerte del Doctor Zavallos concluía la suspensión efectiva de la disposición limitadora del alcance espacial en la actuación de los protomédicos dictada en 1523, que sólo circunstancias excepcionales como la itinerancia europea del emperador habían permitido. Mientras que, con el nuevo reinado, las Cortes retomaron de manera inmediata su preocupación por la actuación de los protomédicos, solicitando sencillamente su supresión, y el traspaso de sus atribuciones de examen y licencia a las justicias municipales, como trataba la petición XXVII de las Cortes de Valladolid de $1558^{83}$, que, con todo, no fue atendida por el rey. La asamblea de Va-

80. Rojo Vega, A., "1556. Testamento del Doctor Diego de Ceballos, Protomédico y Médico de Cámara de S.M.", en https://investigadoresrb.patrimonionacional.es/node/5019. Nombró como albaceas y testamentarios en la villa de Guadalupe al licenciado Simón Ximénez de Guadalupe, cirujano de Su Majestad y Antón de Burgos, vecinos de la villa, y en Valladolid a los boticarios Francisco de Madrid y Lorenzo Díaz.

81. Previamente habían sido enterradas en ella una hija (en 1539), su mujer María (1542) y la suegra de su hijo el comendador don Cristóbal de Ceballos (1560), Fray Arturo Álvarez, O.F.M., "Carlos V y el Real Monasterio de Guadalupe", Miscelánea Comillas 30 (1958) pp. 157-212, p. 182; Fray Arturo Álvarez, O.F.M., "Un ilustre protomédico de Carlos V. El Doctor Ceballos", p. 4. El testamento citado permite precisar la información ofrecida por Álvarez, archivero del monasterio.

82. Siegrist de Gentile-Samudio Azpurúa, N., Dote matrimonial y redes de poder en el Antiguo Régimen en España e Hispanoamérica, Universidad de los Andes, 2006, p. 35.

83. "Petición XXVII. Sobre el examen de los médicos y cirujanos. Item, dezimos que por haver havido en estos reynos prothomédicos que han tenido e usado los officios más para su interese que para el bien público, se han seguido muchos daños en la salud de los hombres y muertes dellos. Porque por dineros e por negociaciones y ruegos han examinado e dado por hábiles, y licencias para curar de medicina e cirugía a muchas personas inhábiles y sin sciencia ni experiencia, y a otros para boticarios y drogueros sin haver los tales médicos y cirujanos estudiado en las universidades principales destos reynos, que son Salamanca, Valladolid, Alcalá de Henares o Bolonia el tiempo que son obligados conforme a los estatutos de 
Iladolid de 1555 se había centrado todavía en la vertiente de la titulación, en su petición LXIII, al pedir que el título de medicina fuese expedido por aquellas universidades en las que constase haber aprobado los cuatro años requeridos para la obtención del grado, y evitar así fraudes derivados del traslado de centro ${ }^{84}$. Sin embargo, el fin de la situación excepcional representada por Zavallos no implicó en adelante una restricción exclusiva de los protomédicos al espacio representado por la Corte y sus cinco leguas de perímetro. Dada su estrecha vinculación por la vía personal, el ejercicio como protomédico extendía el alcance de las funciones de los médicos de Cámara, y daba un carácter doméstico y cortesano al espacio en el que intervenían, más evidente en la Corte y las cinco leguas -sobre el papel, su espacio acotado de control directo de la profesión médica a partir de 1523-, más mediado y difuso a partir de ellas, sobre el soporte institucional ofrecido por el Consejo ${ }^{85}$.

Además, el examen para ejercer en cualquier lugar de Castilla continuó dependiendo de la figura del protomédico ${ }^{86} y$, directamente o por el cauce com-

las dichas universidades e haviéndose graduado por rescriptos o por condes palatinos. E no haviendo platicado con otros médicos e cirujanos antiguos, doctos y de mucha experiencia primero que ussen sus officios, con que estén graduados dos o tres años. Suplicamos a V. M. que de aquí adelante no provea los tales prothomédicos y mande que no los aya, y si alguno estuviere proveydo lo suspenda o revoque. Y provea y mande que ningún médico ni cirujano pueda curar de medicina ni cirugía en ninguna ciudad, villa o lugar destos reynos so buena pena; ni las justicias se lo consientan si ante ella y el regimiento primero no presentare la carta de examen y grados que tuviere en una de las dichas tres universidades o collegio de Bolonia, y un testimonio signado de escrivano público con el dicho o dichos, con juramento de los médicos e cirujanos con quien oviere platicado después de los dichos grados dos años cumplidos por lo menos o más tiempo, affirmándole con juramento los dichos médicos o cirujanos con quien oviere platicado. E que a los boticarios y barveros, y drogueros, e comadres los hagan examinar la justicia e regimiento de las dichas ciudades o villas do ovieren de usar sus officios tomando consigo para el dicho examen dos médicos de sciencia e de experiencia, que hallándolos hábiles les den licencia para usar los dichos officios, y que sin ella no lo puedan usar, con penas, ni las justicias se lo consientan. Suplicamos a V. M. que ansí lo mande proveer y provea, porque será mejor examen y más libre que de los prothomédicos". La respuesta real fue clara: "A esto vos respondemos, que en lo de los prothomédicos se guarden lo que está proveydo e no haya novedad. En lo demás contenido en vuestra petición mandamos a los del nuestro Consejo que venida la relación y parecer de las universidades, como está mandado, lo provean como convenga", en Cortes de los Antiguos Reinos de León y Castilla..., V, pp. 747-748.

84. La respuesta real encargó al Consejo consultar a las universidades al respecto, Cortes de los Antiguos Reinos de León y Castilla..., V, p. 658.

85. A este respecto resulta de interés lo afirmado por Amasuno Sárraga, M. V., Medicina ante la ley. La licentia practicandi y el ejercicio de la medicina en la Castilla medieval, Salamanca 2002, p. 149, respecto a que en tiempo de los Reyes Católicos la intervención del Consejo Real en los asuntos de los alcaldes y examinadores mayores fue cada vez más continua y extensa.

86. Como ejemplo tenemos el examen realizado por Pedro de Caamaño en julio de 1579, quien se desplazó desde Galicia para examinarse como cirujano ante el protomédico y los 
plementario del Consejo, fueron muchas las cuestiones de índole sanitaria más allá de las cinco leguas que dependieron de los protomédicos. A todo ello se añadía el hecho de que, de facto, la movilidad regia sobre el territorio multiplicaba el polo de origen de ese perímetro limitado, representado por la persona real. Dado que el protomédico se hallaba entre el personal médico que la acompañaba en sus desplazamientos, "... mirando y haciendo traer ante sí las Cartas que tuviere noticia son falsas... de las partes donde estuviéremos y de las cinco leguas alrededor, ...". Como señala Clouse, los frecuentes viajes reales permitieron que la práctica regulatoria a cargo de los protomédicos se dejase sentir a lo largo y a lo ancho de los reinos de Castilla ${ }^{87}$. Para Miguel Eugenio Muñoz, en sus conocidas Leyes del Protomedicato, las disposiciones que legalizaban esta itinerancia, contenidas en la Pragmática de 1617, eran coherentes con el alcance ilimitado de la acción de los protomédicos definido en 1477. Este autor, al tratar sobre la facultad que tuvieron para delegar, defendió la idea de que su jurisdicción fue universal, con el argumento de que las disposiciones restrictivas no implicaban derogación tácita ni expresa de la mencionada ley de los Reyes Católicos de 30 de marzo de 1477, que en su primer capítulo afirmaba que los protomédicos y alcaldes examinadores mayores lo eran en todos los reinos y señoríos del rey castellano ${ }^{88}$. Como se apreciaba en la mera validez de los títulos expedidos en la Corte por los protomédicos, en el conjunto del espacio territorial constituido por tales reinos y señoríos ${ }^{89}$.

Posteriormente, conforme a lo contenido en la señalada Pragmática, la frecuente movilidad de los protomédicos se dedujo de la delegación entre ellos, por ausencia del más antiguo más allá de diez leguas de la Corte y su distrito, para visitar las boticas de ella; o también de la referida inspección de licencias médicas y visita de boticas en los lugares que los protomédicos recorriesen y sus cinco leguas circundantes, cuando acompañaban al rey en jornada. Culminación lógica de esta tendencia fue para Muñoz la designación en 1741 de subdelegados del protomedicato más allá del espacio de su

examinadores. Pasada la prueba, recibió licencia para para practicar "en todos los reinos y señoríos de Su Magestad", Parrilla Hermida, M., "Un título de cirujano en 1579", Asclepio (1973) pp. 173-178.

87. Clouse, M. L., Medicine, government and public health in Philip II's Spain..., p. 28.

88. La Pragmática de 1477 en el libro tercero, título 16, ley 1 de la Recopilación de las leyes destos reynos, hecha por la Magestad Católica del Rey don Felipe Segundo nuestro señor....

89. Recopilación de las Leyes, Pragmáticas Reales, Decretos y Acuerdos del Real ProtoMedicato, hecha por encargo, y dirección del mismo Real Tribunal por D. Miguel Eugenio Muñoz, del Consejo de Su Magestad, oidor de la Real Audiencia de Valencia, Académico de Número de la Real Academia de la Historia, subdelegado del Real Protomedicato en la misma ciudad y reyno. En Valencia, en la Imprenta de la viuda de Antonio Bordázar,... Año M.DCC. LI, p. 336. Al respecto, asimismo, Muñoz Garrido, R., Ejercicio legal de la medicina en España (Siglos XV al XVIII). Salamanca 1967, pp. 47-49. 
intervención directa, motivada en su opinión tan solo por una acumulación de tareas $^{90}$ que, con todo, derivaba del referido trasfondo doméstico.

En definitiva, esta circunstancia implicaba desplazar por la plataforma territorial de los reinos una circunscripción móvil de naturaleza cortesana, de tal manera que restricción y proyección espacial fueron compatibles. El fundamento de este proceso fue doméstico, derivado de la usual acumulación de las condiciones de médico de Cámara y protomédico. Proceso que se percibió con especial claridad en el contenido de las cédulas reales de tiempo de Carlos $\checkmark$ estudiadas, que, de facto, suspendieron cualquier limitación territorial en la intervención de los protomédicos que las recibieron, en virtud de la excepcionalidad representada por la ausencia del emperador. Con todo, la coyuntura del acceso de Felipe II al trono renovó la vigencia de la limitación definida en el capítulo de Cortes de 1523.

\section{Bibliografía}

Alonso Cortés, N., Dos médicos de los Reyes Católicos, Separata de Hispania XLV, s.a. Fray Arturo Álvarez, O.F.M., "Carlos V y el Real Monasterio de Guadalupe". Miscelánea Comillas 30 (1958) pp. 157-212.

Fray Arturo Álvarez, O.F.M., “Un ilustre protomédico de Carlos V: el Doctor Ceballos", ABC Sevilla, 14 de noviembre de 1958, pp. 3-5.

Amasuno Sárraga, M. V., Medicina ante la ley. La licentia practicandi y el ejercicio de la medicina en la Castilla medieval. Salamanca 2002.

Barrio Ogayar, J., La organización del Protomedicato en España, Memoria para optar al Grado de Doctor en Medicina, Facultad de Medicina, Universidad de Granada. Dirigida por el Profesor José Luis Valverde López, 1989.

Beltrán de Heredia, V., Cartulario de la Universidad de Salamanca, II. Salamanca 1970.

Beltrán de Heredia, V., Cartulario de la Universidad de Salamanca: la universidad en el Siglo de Oro, IV. Salamanca 1972

Cadenas y Vicent, V. de, Diario del Emperador Carlos V (Itinerarios, permanencias, despacho, sucesos y efemérides relevantes de su vida). Madrid 1992.

Campaner y Fuentes, Á., Cronicón Mayoricense. Noticias y relaciones históricas de Mallorca desde 1229 a 1800. Palma de Mallorca 1984.

Campos Díez, M. S., El Real Tribunal del Protomedicato castellano (Siglos XIV$X I X)$. Cuenca 1999.

90. Recopilación de las Leyes, Pragmáticas Reales, Decretos y Acuerdos del Real ProtoMedicato,..., p. 336, así como Muñoz Garrido, R., Ejercicio legal de la medicina en España..., pp. 48-49. 
Cano Roldán, I., La mujer en el Reyno de Chile. Municipalidad de Santiago, 1981.

Cortes de los Antiguos Reinos de León y de Castilla, publicadas por la Real Academia de la Historia, t. IV. Madrid 1882.

Cortes de los Antiguos Reinos de León y de Castilla publicadas por la Real Academia de la Historia, t. V. Madrid 1903.

Clouse, M. L., Medicine, government and public health in Philip II's Spain: shared interests, competing authorities. Farnham, Burlington 2011.

Cuartero y Huerta, B. y Vargas Zúñiga y Montero de Espinosa, A. de, Índice de la Colección de Don Luis Salazar y Castro, IX. Madrid 1953.

Fernández Álvarez, M., (ed. lit.), Corpus Documental de Carlos V, IV. Salamanca 1979.

Frigo, D. Il padre di famiglia. Governo della casa e governo civile nella tradizione del "economica" tra Cinque e Seicento. Roma 1985.

Frigo, D., "'Disciplinae Rei Familiariae': a Economía como modelo administrativo de Ancien Regime". Penelope. Fazer e desfazer a História 6 (1991), pp. 47-62.

Sebastián García, O.F.M., "Medicina y cirugía en los Reales Hospitales de Guadalupe". Revista de Estudios Extremeños 49 (2003) pp. 11-78.

García Gallardo, E., La documentación carolina en el Archivo Municipal de Murcia (1516-1525). Edición y estudio institucional. Tesis Doctoral Universidad de Murcia, 2017. http://hdl.handle.net/10201/55465

García Gallo, A., (ed.), Libro de las Bulas y Pragmáticas de los Reyes Católicos, I. Madrid 1973.

Gómez Mampaso, V., "Los alcaldes examinadores mayores. Origen y competencia". Boletín de la Real Academia de la Historia 180 (1983), pp. 551-560.

González Arce, J. D., "Los proyectos de ordenanzas generales de médicos, cirujanos y boticarios de Castilla (ca. 1491-1513)". Dynamis 31 (1) (2011) pp. 207-226. https://www.raco.cat/index.php/Dynamis/article/view/248585

Haliczer, S., Los comuneros de Castilla: la forja de una revolución (1475-1521). Valladolid 1987.

Hernández Morejón, A., Historia crítica de la medicina española, I. Madrid 1842.

Jiménez Muñoz, J. M., Médicos y cirujanos en "Quitaciones de Corte". Valladolid 1977.

Keniston, H., Francisco de los Cobos: secretario de Carlos V. Madrid 1980.

Laguna de Paz, J. C., La autorización administrativa. Cizur Menor (Navarra) 2006.

Libro del regimiento de la salud, y de la esterilidad de los hombres y mugeres, y de las enfermedades de los niños y otras cosas utilíssimas. Compuesto 
por el doctor Ávila de Lobera, médico de Su Magestad..., [Valladolid], 1551.

López Terrada, M. L., "Los tribunales del Protomedicato y el Protoalbeiterato", en López Piñero, J. M., dir., Historia de la ciencia y de la técnica en la corona de Castilla, III, Siglos XVI y XVII. Salamanca 2002, pp. 107-125.

Mannori, L., "Giustizia e amministrazione tra antico e nuovo regime", en Romanelli, R. (ed.), Magistrati e potere nella storia europea. Bolonia 1997.

Martínez Millán, J., "Grupos de poder en la Corte durante el reinado de Felipe II: la facción ebolista, 1554-1573", en Martínez Millán, J., coord., Instituciones y élites de poder en la Monarquía Hispana durante el Siglo XVI. Madrid 1992, pp. 137-198.

Martínez Millán, J. (Dir.), La Corte de Carlos V, vol. V, Los servidores de las casas reales. Madrid 2000

Muñoz Garrido, R., Ejercicio legal de la medicina en España (Siglos XV al XVIII). Salamanca 1967.

Parrilla Hermida, M., "Un título de cirujano en 1579", Asclepio (1973) pp. 173178.

Quesada Sanz, J., "Algunos aspectos de la medicina en Murcia durante la época de los Reyes Católicos". Murgetana 6 (1954) pp. 53-97.

Rady, M., Carlos V, Madrid 1991.

Recopilación de las leyes destos reynos, hecha por la Magestad Católica del Rey don Felipe Segundo nuestro señor..., Madrid 1640 [ed. facsímil Valladolid 1982].

Recopilación de las Leyes, Pragmáticas Reales, Decretos y Acuerdos del Real Proto-Medicato, hecha por encargo, y dirección del mismo Real Tribunal por D. Miguel Eugenio Muñoz, del Consejo de Su Magestad, oidor de la Real Audiencia de Valencia, Académico de Número de la Real Academia de la Historia, subdelegado del Real Protomedicato en la misma ciudad y reyno. En Valencia, en la Imprenta de la viuda de Antonio Bordázar,... Año M.DCC.LI.

Rojo Vega, A., "1556. Testamento del Doctor Diego de Ceballos, Protomédico y Médico de Cámara de S.M.", en https://investigadoresrb.patrimonionacional. es/node/5019

Sampietro Solanes, M. J., La comunicación científico-médica en Mallorca (15601760): bibliotecas de médicos, boticarios y cirujanos e introducción de medicamentos chymicos, Tesis Doctoral Universidad de las Islas Baleares, 2015. http://hdl.handle.net/11201/148988

Siegrist de Gentile-Samudio Azpurúa, N., Dote matrimonial y redes de poder en el Antiguo Régimen en España e Hispanoamérica. Universidad de los Andes, 2006. 
Solís de los Santos, J., "Zavallos, Diego de", Diccionario Biográfico Español (edición electrónica), http://dbe.rah.es/biografias/86598/diego-de-zavallos

Valverde, J. L., "El Tribunal del Protomedicato: composición, funciones, jurisdicción". Cuadernos Informativos de Derecho Histórico Público, Procesal y de la Navegación 1 (1986), pp. 7-28.

VV. AA., Colección de historiadores de Chile y documentos relativos a la historia nacional. Imprenta del Ferrocarril, 1898. 


\section{Apéndice documental}

1. Cédula Real de Carlos V en Augusta, 12 de septiembre de 1550 (AGS. Consejo Real de Castilla, leg. 93, no 5-I, f. 60r.-v.)

"El Rey. Presidente y los del n[uest]ro Consejo. Ya sabéys cómo yo mandé dar y dí para uosotros una my çédula firmada de my mano del tenor sigui[ent]e. El Rey. Presydente y los del n[uest]ro Consejo, el doctor Çauallos n[uest]ro p[ro]thomédico nos a hecho relaçión q[ue] usando su ofi[ci] o como deuía y no se q[ue]xando ninguno dél, el n[uest]ro fiscal le acusó diziendo q[ue] se entremetía a uisytarlo y le estaua prohibido por no ser de su oficio, sobre lo qual demás de le au[er] condenado en çiertas penas auéys man[da]do p[ar]a q[ue] sea al[ca]lde y exsamynador mayor desos n[uest] ros rrey[n]os y señoríos de los físycos y çirujanos y boticarios ansy ombres como mugeres prohibiendo q[ue] no exsamyne a drogueros ni especieros y parteras ponyéndole en el d[ic]ho of[ici]o otras limitaciones en derogaçión de los títulos y prouisiones que de nos tiene y de las pregmáticas hechas por los cathólicos reyes n[uest]ros agüelos q[ue] ayan gloria de q[ue] tiniéndose por muy agrauiado a suplicado fuésemos seruido de mandar q[ue] le dexéis usar el d[ic]ho of[ici]o conforme al título y prouisyón que de nos tiene sin le poner en ello ninguna limitación o como la n[uest]ra m[erce]d fuese. Y nos tinyendo respeto a algunas causas q[ue] nos mveuen a ello uos mandamos que en guardando se en todo las leyes y pregmáticas desos n[uest]ros reynos en lo demás q[ue] toca a la exención de las otras limitaciones que nveuamente se an dado para el uso y exerçiçio del d[ic]ho oficio por agora sobreseáys y no se haga nouedad en lo que hasta aquí se a fecho entre tanto q[ue] plaziendo a Dios boluamos a esos rreynos, porq[ue] entonces se myrará y sobre platicado se proueerá lo q[ue] más conuenga al bien desos $\mathrm{d}[\mathrm{ic}]$ hos $\mathrm{n}$ [uest]ros rey[n]os. Fecha en Bruselas a ueynte e tres de diziembre de myll e qui[nient]os e quarenta y nveue años. Yo el rrey por man[da]do de Su Mag[esta]d Fran[cisc]co de Eraso. E agora el d[ic]ho doctor Çauallos nos ha hecho relaçión q[ue] auiendo os p[re]sent[a]do la d[ic]ha n[uest]ra cédula y pedidoos la cumpliésedes no lo auéys querido hazer ny responder a ella, antes auéys man[da]do q[ue] se junte con el p[r]oceso q[ue] n[uest]ro $\operatorname{Pr}[$ ocurad] or fiscal hizo contra él en q[ue] dize que recibe agrauio y daño, suplicándonos lo remediásemos mandando q[ue] conforme al título q[ue] de nos tiene y çédula q[ue] después se le concedió pueda usar el d[ic]ho su off[ici]o o como la n[uest]ra m[e]r[ce]d fuese. Y tiniendo consyderaçión a las causas porq[ue] le damos la $d[i c]$ ha $n$ [uest]ra çédula que en esta ua yncorporada uos mandamos la ueáys y la guardéys e cumpláys según y como en ella se q[ontie]ne syn poner en ello escusa ny dilación alg[un]a y no fagades ende al. Fecha en Augusta a doze días de set[iembr]e de myll e qui[nient] os y zinquenta años. Yo el rey. Por mandado de Su Mag[esta]d Fran[cis]co de Eraso" 
2. Traslado de una Cédula Real de Carlos V en Augusta, 18 de mayo de 1551 (AGS. Consejo Real de Castilla, leg. 93, no 5-I, ff. 64r.-65r.)

"Por quanto la serenísyma emperatriz y reina $\mathrm{n}$ [uest]ra muy cara y muy amada muger q[ue] aya gloria mandó dar e dio una su cédula y sobre cédulas della firmadas de su mano del thenor siguiente: La Reyna. Corregidores, asystentes, gobernadores, al[ca]ldes, alguaziles, merinos y otras just[ici]as quales quier de todas las ciudades, uillas y lugares de los n[uest]ros reynos e señoríos y a cada uno de bos en u[vest]ra juridiçión. Sabed q[ue] yo mandé dar e dí una mi çédula e sobre çédula firmada de my mano e señalada de los del n[uest]ro Consejo su thenor de la qual es esta q[ue] se sygue: La Reyna. [...]. Sabed q[ue] yo mandé dar e dí una my çédula firmada de mi nonbre e señalada de los del n[uest]ro Consejo e refrendada de $\mathrm{Ju}^{\circ}$ Uázq]ue]z n[uest]ro secret[ari]o su thenor de la qual es este q[ue] se sigue: La Reyna. [...]. Sabed q[ue] yo mandé dar e dí una my çédula firmada de my nombre e señalada de los del n[uest]ro Consejo e refrendada de $\mathrm{Ju}^{\circ}$ Bázquez n[uest]ro secret[ari]o su thenor de la qual es este que se sigue: La Reyna. Por quanto durante la ausencia del emperador e rey my señor conbiene nonbrar prothomédicos q[ue] examynen los físicos e çurujanos e boticarios e barberos q[ue] se bienen a examinar porq[ue] a causa de no auer quién los exsamyne (sic) se detienen muchos días en n[uest]ra Corte haziendo gastos y expensas y alg[un]os dellos diz q[ue] se atreben a usar de los d[ic]hos ofiçios syn ser esamynados de q[ue] podrían seguir muchos peligros e inconbinyentes e por los euitar y excusar e por otros justos respetos uisto e platicado por los del n[uest]ro Consejo fue acordado q[ue] debíamos mandar nombrar dos buenas p[er]sonas q[ue] por algún t[iem]po tubiesen cargo de exsamynar los $\mathrm{d}$ [ic]hos físicos y çurujanos e boticarios. Por ende acatando las letras e buena esperiencia e buena conçiençia de uos el dotor Miguel Çorita de Alfaro, n[uest] ro físico e de uos el dotor Salaya médico estante en n[uest]ra Corte my m[e]r[ce] $\mathrm{d}$ e boluntad es q[ue] durante la absençia del emperador e rey my señor e por el t[iem]po q[ue] n[uest]ra m[erce]d e boluntad fuere seáys n[uest]ros prothomédicos y exsamynadores e uos damos ente[ra] facultad p[ar]a q[ue] todas las p[er] sonas q[ue] quysyeren usar de los d[ic]hos of[ici]os de físicos e çurujanos, boticarios e barberos e q[ue] se vuieren de exsamynar ante uosotros los exsamyneys e déys u[vest]ras cartas de exsamen firmadas de u[vest]ros nombres e llebéys por razón dello los d[e]r[ech]os q[ue] Ileban e podían llebar los d[ic]hos n[uest] ros prothomédicos q[ue] an sydo hasta aquí, contando q[ue] las p[er]sonas q[ue] exsamynáredes las exsamynéys anbos a dos juntamente e no el uno syn el otro e con q[ue] no hos entremetáys a llamar ny apremyar a nyng[un]a p[er]sona salbo a aquellos q[ue] stán en n[uest]ra Corte e dentro de cinco leguas alrededor della e q[ue] no estvuieren exsamynados o obieren estado en costunbre de curar mucho t[iem]po e q[ue] las p[er]sonas q[ue] examináredes las exsamynéys en n[uest]ra Corte e no fuera della ny déys poder a otra p[er]sona q[ue] lo aga e conq[ue] ansymysmo no uos entremetáys a exsamynar ni ensalmadores ny drogueros ny otra p[er]sona alguna más de los susod[ic]hos ofiçios e çurujanos e 
boticarios e barberos como de suso se contiene. Fecha en la uilla de Madrid a ueynte quatro días del mes de set[iembr]e de myll e qui[nient]os e ueynte e nuebe a[ñ] os. Yo la reyna. Por mandado de Su M[a]g[es]t[ad] Ju Uázquez. E agora los $\mathrm{d}$ [ic] hos dotores Alfaro e Salaya $\mathrm{n}$ [uest] ros prothomédicos me hizieron relaçión q[ue] algunas bezes acaesçe q[ue] uno dellos solamente se halla en algunas desas $\mathrm{d}$ [ic]has ciudades, uillas e lugares, quyere usar del $\mathrm{d}$ [ic]ho of [ici] o conforme a la d[ic]ha my çédula diz q[ue] uos las d[ic]has n[uest]ras just[ici] as e otras p[er]sonas de los pueblos no se lo consientes de q[ue] se syguen muchos daños e ynconbinyentes e me suplicaron e pidieron por m[e]r[ce]d hos mandase q[ue] libremente les dexásedes exerçer sus ofiçios por sus p[er]sonas o qualquier dellos no embargante que estubiesen absentes de n[uest] ra Corte e fuera de las cinco leguas della pueda p[er]sonalmente syn lo cometer a otra p[er]sona usar del d[ic]ho of[ici]o de n[uest]ros p[r]othomédicos, hos mando que libremente los dexéys e consintáys usar del d[ic]ho of[ici]o de n[uest]ros prothomédicos a cada uno dellos por sý haziendo la d[ic]ha uisytaçión p[er] sonalmente en los casos y cosas contenydas en la d[ic]ha my çédula q[ue] desuso ua incorporada sin q[ue] en ello le pongáys ny consintáys poner embargo ny ynpedimento alguno e no fagades ende al. Fecha en la uilla de Madrid a ueynte días del mes de junyo de myll e qui[nient]os y treinta a[ñ]os. Yo la Reyna. Por mandado de Su Mag[esta]d Juan Uazquez. E agora los d[ic] hos dotor ÇauaIlos y Nicolás de Florenes n[uest]ros prothomédicos nos suplicaron y pidieron por m[e]r[ce]d que pues ellos usaban los d[ic]hos of [ici]os de $\mathrm{n}$ [uest] ros prothomédicos mandase q[ue] las $\mathrm{d}$ [ic]has mys çédulas e sobre çédulas della q[ue] desuso uan incorporadas q[ue] ansý mandé dar a los d[ic]hos dotores Alfaro e Salaya se entendiesen e guardasen con ellos bien e ansý e a tan cumplidamente como sy a ellos fueran dadas e concedidas, o como la n[uest]ra m[e]r[ce]d fuese. E yo acatando lo susod[ic]ho túuelo por bien. Por ende yo uos mando a todos y cada vno de uos en u[vest]ra juridición según $\mathrm{d}[\mathrm{ic}]$ ho es q[ue] beays la d[ic]ha my çédula e sobreçédula della q[ue]e desuso uan incorporadas e las guardéys e cunpláys e agáys guardar y cunplir con los d[ic]hos dotores Çauallos y Nycolás de Florenes n[uest]ros p[r]othomédicos y con cada uno dellos en todo e por todo como en ella se cont[ien]e bien e ansy e a tan cumplidam[en]te como sy a ellos fueran dadas e conçedidas e según están mandadas guardar a los d[ic]hos dotores Alfaro e Salaya e contra el thenor e forma de lo en esta my çédula contenydo no bayáis ni paséys ny consintáys yr ny pasar por alguna manera. Hecho en la uilla de Ual[lado]lid a beynte e cinco días del mes de nobienbre de myll e qui[nient]os y treynta y siete años. Yo la Reyna, por mandado de Su Mag[es]t[ad] Jư Uázq[ue]z. Agora por parte del d[ic]ho dotor Çaballos n[uest]ro prothomédico se nos a hecho relaçión q[ue] quando le acaesçe pasar de camino por algún lugar las just[ici]as dellos no le an querido guardar las d[ic] has çédulas antes se an puesto en ynpedirle q[ue] no exerçite el $d$ [ic]ho (f. 65 r.>) su of [ici]o de prothomédico de q[ue] se siguen muchos daños e ynconbinyentes a la buena gobernaçión e bien pú[bli]co de los d[ic]hos n[uest]ros reynos suplicándonos fuese[m] os s[er]bidos de mandar q[ue] le dexen usar y exerçer el d[ic] 
ho su ofiçio de prothomédico conforme al títu[l]o q[ue] dél tiene o como la n[uest]ra m[erce]d fuese e nos auémoslo auido por bien. Por ende por la p[re] sente mandamos a todos los corregidores e asystentes, gobernadores, al [ca]d[e] s, alguaziles, merinos, prebostes e otras just[ici]as e juezes qualesquier de todas las çiudades, uilla e lugares de los n[uest]ros reynos e señoríos de Castilla e a cada uno e qualesquier de uos a quien esta my cédula fuere mostrada e lo en ella contenydo toca e atañe q[ue] beáys las d[ic]has çedula e sobreçédulas q[ue] en ella uan encorporadas y el títu[l]o e p[r]obisyones q[ue] el d[ic]ho dotor Çaballos tiene de nos e de n[uest]ro Consejo p[ar]a el uso y exerçicio del d[ic]ho of[ici]o e guardándolas e cumpliéndolas conforme a ellas le dexéys e consyntáys usar y exerçer el d[ic]ho su of[ici]o de prothomédico en estos n[uest]ros reynos e señoríos libremente syn lo poner embaraço ny ynpedimento alg[un]o no embargante qualquier ley o premática q[ue] en cont[rari]o aya con las quales por sola esta uez Nos dispensamos quedando para todo lo demás en su fuerça e uigor contanto q[ue] el d[ic]ho dotor por su p[er]sona syn lo cometer a otra p[e]rsona use y exerza el d[ic]ho of[ici]o de prothomédico e las uisytaçiones tocantes a él las aga en p[re]sencia de uos los corregidores o juezes de residençia o su lugartheni[ent]e o al[ca]ldes e just[ici]as hordinarios de las çiudades, uillas o lugares donde se hallare y estubiere según e de la man[er]a q[ue] lo exerçita e usa en n[uest]ra Corte e cinco leguas alrededor y los unos ni los otros fagades ende al. Fecha en Augusta a diez y ocho de mayo de mil e qui[nient]os e cinq[uent]a e un años. Yo el Rey. Por mandado de Su Mag[esta]d Fran[cis]co de Erasso". 